\title{
Aeroelastic energy harvesting from statistically representative gust encounters
}

\author{
Marco Saporito ${ }^{1}$, Andrea Da Ronch ${ }^{2, *}$ \\ University of Southampton, Southampton, SO17 1BJ, United Kingdom
}

\begin{abstract}
The mission of high-altitude long-endurance unmanned aerial vehicles is limited by energetic considerations. This paper explores, for the first time in the open literature, statistic estimates of the potential energy that may be harvested from gust encounters along a representative flight mission. The work is built around three objectives: 1) investigate the influence that the configuration of the piezoelectric inserts, at equivalent total mass, has on the energy harvesting performance; 2) assess the energetic balance between the harvested energy from gust encounters and the energy needed by an actuation system to achieve a certain gust load alleviation; and 3) discuss the potential weight saving of batteries when employing piezoelectric inserts. The test case is for the flexible wing of a high aspect ratio unmanned aerial vehicle flying in low speed flight.
\end{abstract}

Keywords: Piezoelectric, Energy harvesting, HALE aircraft, Aeroelasticity

\section{Nomenclature}

$\delta \quad$ Flap deflection

$\eta \quad$ Electro-mechanical coupling factor

$\mathscr{H} \quad$ Heaviside step function

$\phi \quad$ Wagner's function

* Corresponding author

Email address: a.da-ronch@soton.ac.uk (Andrea Da Ronch)

${ }^{1} \mathrm{PhD}$ student.

${ }^{2}$ New Frontiers Fellow \& Lecturer, Faculty of Engineering and Physical Sciences. 
$\psi \quad$ Kussner's function

$\rho \quad$ Air density

$\theta \quad$ Torsional deformation of the wing and angle of attack

$\varepsilon_{z z}^{S} \quad$ Permittivity constant under constant strain

${ }_{10} \xi$ Dimensionless vertical displacement of the elastic axis, $h / b$ (positive downward)

A Cross section of the wing

a Dimensionless distance of the elastic axis to midchord

$A_{1}, A_{2}$ Coefficients used in the Wagner's function

$A_{3}, A_{4}$ Coefficients used in the Kussner's function

${ }_{15} A_{p} \quad$ Horizontal projection of the surface of piezoceramic elements

$b \quad$ Aerofoil half-chord

$b_{1}, b_{2}$ Coefficients used in the Wagner's function

$b_{3}, b_{4}$ Coefficients used in the Kussner's function

c $\quad$ Aerofoil chord

${ }_{20} C(k)$ Theodorsen's function

$c_{F} \quad$ Dimensionless distance of the flap hinge to midchord

$C_{p} \quad$ Equivalent capacitance of the piezoelectric inserts

$c_{x x} \quad$ Elastic modulus in the $x$-direction

$c_{x x}^{E} \quad$ Elastic modulus of the piezoceramic at constant electric field

$25 \quad d \quad$ Distance of centre of gravity from elastic axis

$D_{z} \quad$ Electric displacement in the $z$-direction

$E, E_{a}$ Harvested and actuation energy, respectively 
$E_{z} \quad$ Electric field in the $z$-direction generated by the piezoceramic

$E_{z}^{e} \quad$ Electric field in the $z$-direction applied to the piezoceramic

30 $e_{z x} \quad$ Piezoelectric constant

EI Bending stiffness

$F_{z} \quad$ External load per unit span in the $z$-direction

$g \quad$ Gain for feedback control

GK Torsional stiffness

${ }_{35} \quad H \quad$ Flight altitude

$h \quad$ Vertical displacement of the elastic axis, positive downward

$I_{y} \quad$ Moment of inertia of the wing section about the $y$ axis

$J \quad$ Section moment of inertia with respect to the elastic axis

$k \quad$ Reduced oscillation frequency, $\omega b / U$.

40 $\quad L \quad$ Lift per unit span

$l_{p} \quad$ Length of the piezoceramic insert ( $x$-direction)

$l_{w} \quad$ Wing semispan ( $x$-direction)

$M \quad$ Pitching moment per unit span

$m \quad$ Mass per unit span

${ }_{45} \quad M_{b} \quad$ Bending moment about the $y$-axis

$M_{h} \quad$ Aileron hinge moment per unit span

$M_{\theta} \quad$ External twisting moment per unit span (around the $x$-axis)

$N \quad$ Number of beam elements

$N_{F} \quad$ Number of flapped elements 
$P, P_{a}$ Harvested and actuation power, respectively

$P_{x x} \quad$ Axial stress ( $x$-direction)

$Q \quad$ Electrical charge

$R_{e q} \quad$ Equivalent load resistance

${ }_{55} \quad s_{p} \quad$ Width of the piezoceramic (y-direction)

$S_{x x} \quad$ Axial strain ( $x$-direction)

$t \quad$ Dimensional time

$T_{i} \quad$ Coefficients for aerodynamic forces due to flap deflection, from ref [1]

$t_{p} \quad$ Thickness of the piezoceramic ( $z$-direction)

${ }_{60} t_{w} \quad$ Thickness of the wing

$U \quad$ Free-stream velocity

$u \quad$ Vertical displacement of the elastic axis in the $z$-direction

$w_{3 / 4}$ Vertical velocity of the fluid particle at the three-quarter point of the airfoil

$x_{p} \quad$ Abscissa where the piezoelectric insert starts

${ }_{65} x_{F 1 / 2}$ Span-wise starting/ending location of the aileron surface

\section{Introduction}

In the modern aerospace setting, increasing efforts are made to enhance aeroplane performance through the development of light-weight aeroplanes. This trend is visible in many fields, from large civil and commercial transport aircraft to the new generation of High-Altitude Long-Endurance (HALE) manned and unmanned air vehicles, Fig. 1. Within this latter class, many prototypes have already been successfully flown powered by solar energy or equipped with hydrogen-powered 


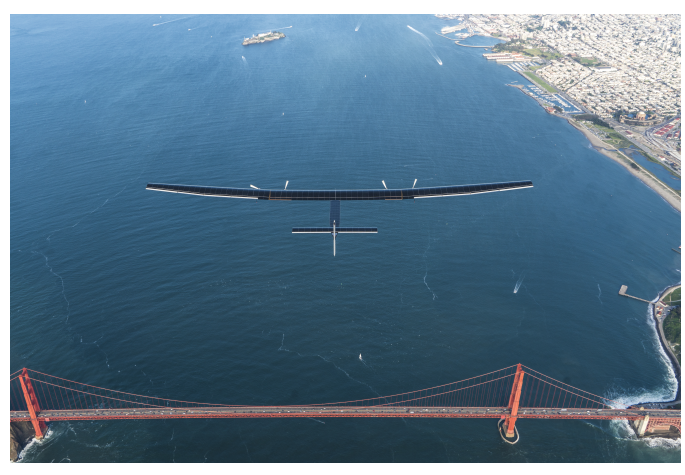

(a) Solar Impulse [5].

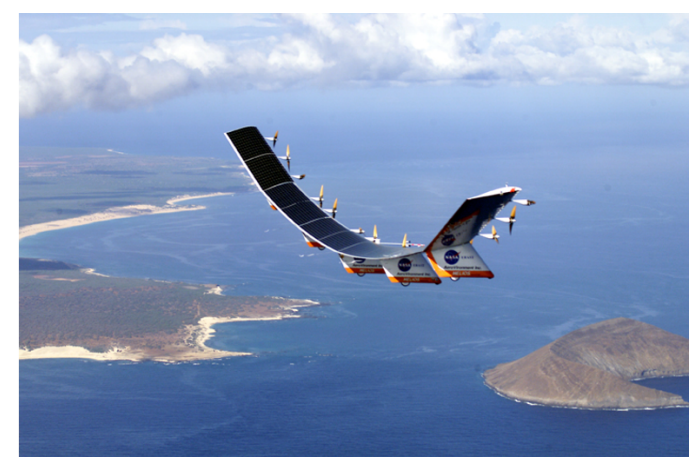

(b) Helios prototype [6].

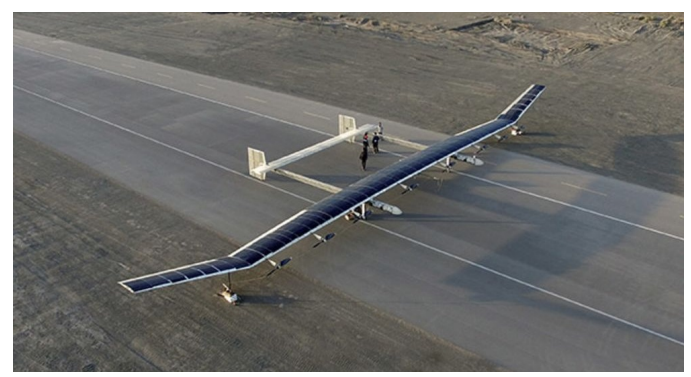

(c) China Academy of Aerospace Aerodynamics (CAAA) solar drone [7.

Figure 1: Examples of very light, solar-powered HALE aircraft.

engines, reaching almost total energetic autonomy, in order to remain in flight for long periods without need to interrupt the mission for refuelling.

Due to the high efficiency demanded in this type of applications, very light-weight structures, high aspect ratio and allowance for flexibility are required. In this regard, a large body of work investigated methods to deal efficiently with high flexibility in aircraft structures and coupling between aeroelasticity and flight dynamics. To name some relevant examples, Murua et al. [2] studied the effect of high flexibility in open loop flight dynamics, Shearer et al. [3] investigated nonlinear effects in very flexible aircraft dynamics, Paulino et al [4] developed an approach for real-time flight simulation of flexible aircraft.

The requirements of light, slender and flexible structures give rise to at least two issues. First, there is a need to minimise weights, including weights of engines, power plants and energy storage devices or fuel. Second, in the context of flight and structural dynamics, it is crucial to deal 
with strong sensitivity to atmospheric turbulence, due to very low wing loadings, and to prevent dangerous phenomena, such as flutter, divergence and fatigue.

Consequently, appropriate controllers must be carefully designed, and attention must be paid towards the energetic demand of actuators. Therefore, optimisation is essential to find a compromise between control effectiveness and energy consumption. A large body of work on aeroelastic control for flexible airframes was found in the literature (the reader is invited to refer, for example, to [8], [9] and [10]).

It is clear then that energy, its production and its storage are crucial questions. Batteries are widely diffused means of energy storage in aerospace applications. Apart from their weight, batteries are also affected by the need to interrupt the mission for their replacing or recharging. Furthermore, they introduce hazards in some environmental conditions since they may suffer from thermal runaway, or may ignite and even explode due to short-circuit, extreme temperatures, or inappropriate charge or discharge, not to forget poor design or manufacturing [11].

An alternative way to reduce the penalties of batteries is the autonomous production of energy during flight. In recent years, a large effort has been made to harvest energy from alternative sources not exploited to date, and this is especially true when dealing with very light unmanned aerial vehicles where each kind of energy available would contribute to better performance and longer missions.

Important advantages of energy harvesting (EH) are that: (a) it allows a continuing flight without need for battery recharging; (b) it reduces the costs and time related with physical installation, replacement and maintenance of batteries [11] [12]. This is especially interesting for systems that operate in remote areas with limited power supply and maintenance, and with the requirement of long service time.

The main energy sources for aerospace applications include wind, solar radiation, and mechanical vibration. Among these EH approaches, the study on aircraft solar energy is quite mature, and, compared with other techniques, photo-voltaic conversion provides high power output density ([1] [13). Solar cells have been practically and successfully implemented in HALE aircraft (see Fig. 1). Nevertheless, harvesting sufficient energy to ensure a sustained flight also throughout the night is still a challenging task. This becomes more critical for smaller scale aircraft because of the lower aerodynamic performance compared to HALE configurations. Furthermore, the design of a solar EH module involves complicated trade-offs, and the expense of solar EH systems is still relatively 
large.

An additional, attractive source of energy in atmospheric flight is turbulence. The energy carried by the gust and transferred through the induced aeroelastic vibrations may be harvested by appropriate transducers, and can be used to recharge on-board batteries and to feed low power consumption devices, making theme self-sufficient. Therefore, it is worthwhile to explore techniques such as piezoelectric (PZT) or vibrational EH. A large body of work has been presented to explore piezoelectric EH in aeroelastic applications, for different configurations. For instance, Wu et al., Bae and Inman, Abdelkefi et al. (14], [15, [16]) investigated airfoil-based aeroelastic energy harvesters, Piñeirua et al. ([17]) studied EH from aeroelastic vibrations of cantilevered plates, Bibo and Daqaq, 2014, Yang et al., 2013 (18, [19]) focused on bluff bodies with different cross sections , Xiang et al., Bruni et al., Y. Wang and D.J. Inman ([20, 21], 22] ) studied applications for small wings, in the latter case with attention to simultaneous EH and control.

Most studies fail to investigate EH devices for realistic aerospace applications ([1]), and, from the open literature, it appears that a feasibility study of EH technology on a real scale configuration has never been reported to date. Therefore, the aim of this work is to pursue a preliminary estimation on EH performances for true-scale applications, with the primary objective of the statistical estimation of the harvestable energy in a representative flight. To this goal, some preliminary analyses were carried out in order to select the most effective installation configuration for the PZT inserts. Moreover, since oscillations control is a critical issue in this kind of applications, the energy demand of an aileron control system for gust-loads alleviation was evaluated and compared with the energy income of the harvesting system.

Section 2 describes the derivation of the theoretical and then of the numerical model used for the following analyses. Section 3 presents the validation of the model. The procedure followed is outlined in Section 4, where details are given about the simulation settings, the definition of a representative flight mission, the test case adopted and the design of a control law for gust-loads alleviation. Results are discussed in Section 5. Finally, conclusions are given in Section 6

\section{Model description}

The model consists of a clamped wing with piezoelectric elements attached to the upper and lower skin, as shown in Fig. 2. The piezoceramic elements can be linked in series or in parallel, 
and more than one pair can be used, located along the wing-span (see Sec. 4.2). The wing is also

equipped with one (or more if desired) flap actuator (not shown in the figure) for control purpose.

The characteristic slenderness of wings in HALEs has motivated descriptions of the structural dynamics through beam models and of the unsteady aerodynamics by means of 2-D strip theory. Figure 3 shows all the parameters of the two-dimensional aeroelastic model used to describe aerodynamics at each wing section.

\subsection{Piezoelectric constitutive relations}

For each pair of symmetric PZT patches, shown in Fig. 22 one matrix equation containing the piezoelectric constitutive equations must be written. The assumption here is linear behaviour, and the only contribution considered relevant is the coupling between the longitudinal stress-strain field and the electric field in the vertical direction. The effect of shear deformation induced by twist on the piezoelectric effect is of minor importance if compared with that arising from bending deformations and it is therefore neglected, so that the torsional dynamics is treated as uncoupled. Within these hypotesis, the PZT constitutive equations are as follows (see [21):

$$
\left[\begin{array}{c}
P_{x x} \\
D_{z}
\end{array}\right]=\left[\begin{array}{cc}
c_{x x}^{E} & -e_{z x} \\
e_{z x} & \varepsilon_{z z}^{S}
\end{array}\right]\left[\begin{array}{c}
S_{x x} \\
E_{z}^{e}
\end{array}\right]
$$

where $P_{x x}$ and $S_{x x}$ are, respectively, the axial stress and strain ( $x$-direction), and $E_{z}^{e}$ is the external (imposed) electric field in the $z$-direction (the $z$-axis starting from the neutral axis location). If $E_{z}^{e}$ is applied, an amount of electric displacement $D_{z}=\varepsilon_{z z}^{S} E_{z}^{e}$ will appear at the surface. The field generated by this charge separation will be opposite to the applied field, that is:

$$
E_{z}=-E_{z}^{e}
$$

Since the interest is on the field generated by the material, $E_{z}$ will be used instead of $E_{z}^{e}$, and the constitutive equations will present an inverted sign in the second column:

$$
\left[\begin{array}{c}
P_{x x} \\
D_{z}
\end{array}\right]=\left[\begin{array}{cc}
c_{x x}^{E} & e_{z x} \\
e_{z x} & -\varepsilon_{z z}^{S}
\end{array}\right]\left[\begin{array}{c}
S_{x x} \\
E_{z}
\end{array}\right]
$$




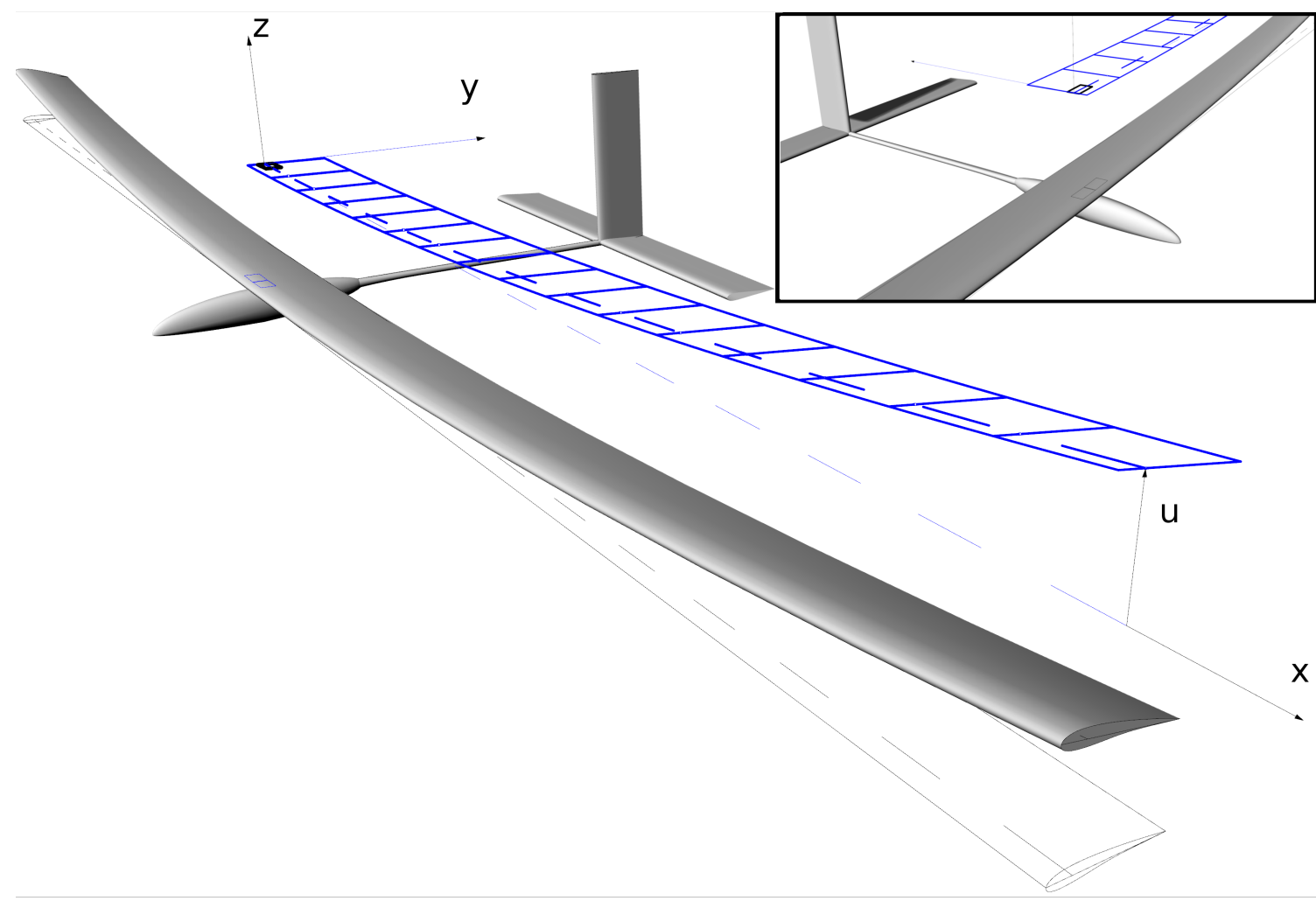

(a) 3D view of the aircraft (grey) with the corresponding wing model (blue) used in this paper. The PZT patches are highlighted in the top-right view.

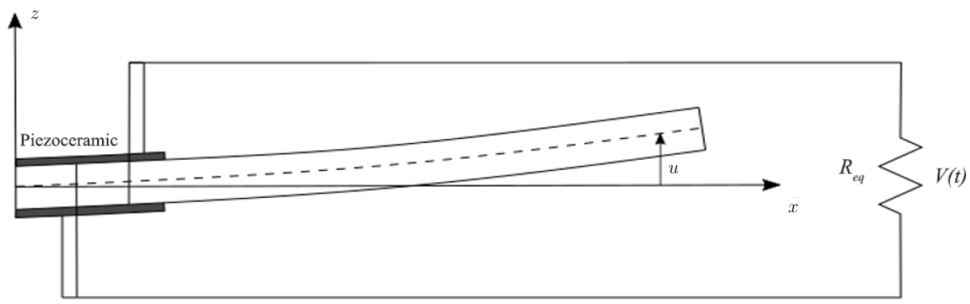

(b) Schematics of pzt installation.

Figure 2: Model of the wing of a representative real-scale HALE aircraft: the wing is clamped with two symmetric PZT inserts installed at the root and connected in parallel. The wing oscillates in pitch and plunge degrees of freedom. Linear beam and 2D strip formulations are used for the aeroelastic model. 


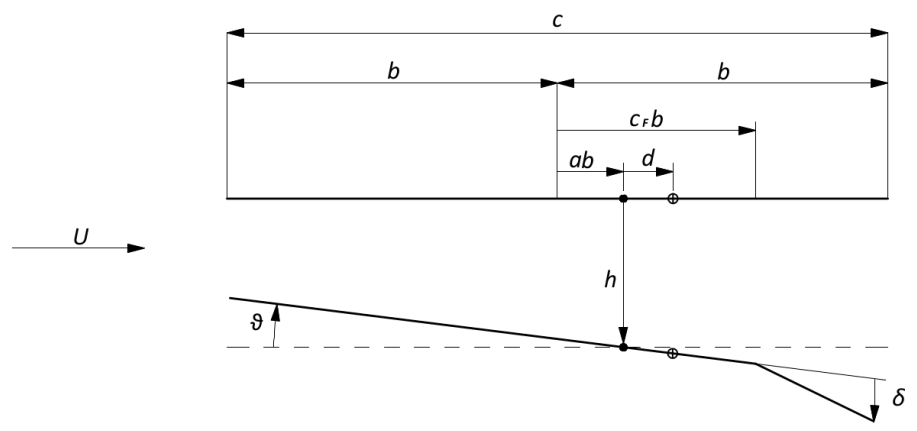

Figure 3: Mean-line of the aerofoil. $\theta$ and $h$ denote pitch and plunge, respectively.

\subsection{Coupled piezo-structural bending equation}

Considering the first row of Eq. (1) as the expression for the stress, the bending moment is:

$$
M_{b}=\int_{A}\left(c_{x x} S_{x x}+e_{z x} E_{z}\right) z d A
$$

where integration is over the wing cross section $A$. Note that the elastic modulus $c_{x x}^{E}$ has been replaced by $c_{x x}$ because in this form it can denote both the stiffness of the structural material and that of the piezoceramic, depending on where the equation is applied.

From the Euler-Bernoulli beam theory, the axial strains can be expressed as

$$
S_{x x}=-z \frac{\partial^{2} u}{\partial x^{2}}
$$

where $z$ is the vertical coordinate measured from the neutral axis. Now, assuming a thin piezoelectric insert, the electric field can be considered constant along its thickness $t_{p}$, the voltage generated is $V=E_{z} t_{p}$. Substituting this equation, as well as Eq. (3), inside Eq. (2), it gives:

$$
M_{b}=-c_{x x} I_{y}(x) \frac{\partial^{2} u}{\partial x^{2}}+\left(\frac{1}{t_{p}} \int_{A} e_{z x} z d A\right) V(t)
$$

The term in brackets on the right-hand side of Eq. (4) is referred to as electro-mechanical 
coupling term (see ref. [21]), and it is given by:

$$
\eta(x)=\frac{1}{t_{p}} \int_{A} e_{z x}\left[\mathscr{H}\left(x-x_{p}\right)-\mathscr{H}\left(x-x_{p}-l_{p}\right)\right] z d A
$$

in which $e_{z x}$ is expressed in terms of Heaviside step function, since this term is present along the $x$-dimension only when the piezoelectric material exists, that is, referring to Fig. 4 when $x_{p} \leq x \leq x_{p}+l_{p}$, where $x_{p}$ is the abscissa where the piezoelectric insert starts, and $l_{p}$ its length.

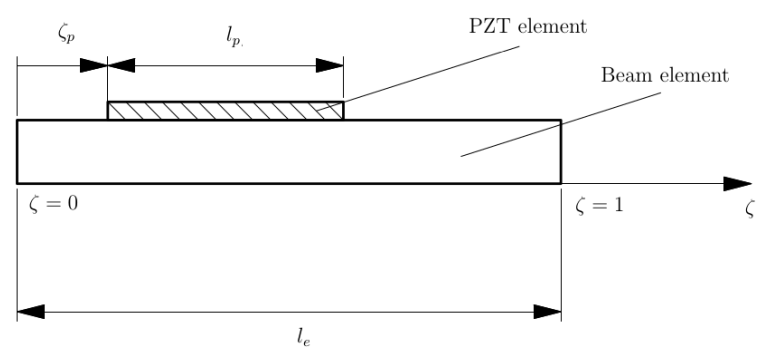

Figure 4: Scheme of a beam element with a PZT insert. Note that $\zeta$ is the nondimensional local element abscissa, while $l_{e}$ and $l_{p}$ are dimensional lengths. This is why their ratio $l_{p} / l_{e}$ appears in Eq. 20. Since the integral is calculated within the element length, that is $0 \leq \zeta \leq 1, l_{p}$ must be contained within this range. If $l_{p}>l_{e}$ is required, then two or more piezoelectric elements must be used.

Now, the dynamic bending equation is obtained writing the equilibrium (in terms of forces per unit span) between the inertial load, the elastic force, and the external aerodynamic load $\left(F_{z}\right)$. Considering also the coupling with the torsional degree of freedom, this yields:

$$
m(x) \frac{\partial^{2} u(x, t)}{\partial t^{2}}-m(x) d(x) \frac{\partial^{2} \theta(x, t)}{\partial t^{2}}+\frac{\partial^{2}}{\partial x^{2}}\left(c_{x x} I_{y}(x) \frac{\partial^{2} u(x, t)}{\partial x^{2}}\right)-\frac{\partial^{2} \eta(x)}{\partial x^{2}} V(t)=F_{z}(x, t)
$$

Equation (6) is the first coupled equation of motion, expressing the bending equilibrium between inertial forces, internal forces, external loads and electric forces.

\subsection{Coupled piezo-structural electric equation}

Differentiating the second row of Eq. (1) with respect to time, and then multiplying it by $d A_{p}$ and integrating along the horizontal surface of the PZT $A_{p}$ - which is its largest plane -, yields:

$$
\int_{A_{p}} e_{z x} \frac{d S_{x x}}{d t} d A_{p}-\int_{A_{p}} \varepsilon_{z z}^{S} \frac{d E_{z}}{d t} d A_{p}=\int_{A_{p}} d \dot{Q}
$$


Here the electric displacement was expressed as $D_{z}=d Q / d A_{p}$.

The strain $S_{x x}$ is defined by Eq. (3), and, as done before, the electric field can be expressed in terms of voltage. Thus, Eq. (7) can be rewritten as:

$$
-\int_{A_{p}} e_{z x} z \frac{\partial^{3} u}{\partial x^{2} \partial t} d A_{p}-\int_{A_{p}} \varepsilon_{z z}^{S} \frac{1}{t_{p}} \frac{d V}{d t} d A_{p}=\dot{Q}
$$

Now, in a configuration with two identical piezoceramics connected in parallel, $d A_{p}=2 s_{p} d x$, and $z$ is evaluated at the medium surface of the piezoceramic, that is $z=\left(t_{w}+t_{p}\right) / 2$. Furthermore, because of Ohm's law, $\dot{Q}=V / R_{e q}$. Thus, Eq. (8) becomes:

$$
\int_{0}^{l_{p}} 2 s_{p} e_{z x} \frac{\left(t_{w}+t_{p}\right)}{2} \frac{\partial^{3} u}{\partial y^{2} \partial t} d x+C_{p} \frac{d V}{d t}+\frac{V}{R_{e q}}=0
$$

Here, the capacitance of the piezoceramic appears in the form $C_{p}=\frac{2 \varepsilon_{z z}^{S} s_{p} l_{p}}{t_{p}}$.

Now, developing the expression for $\eta(x)$ of Eq. [5], in which the integration is made along the cross section, it gives:

$$
\begin{aligned}
\eta(x) & =\frac{1}{t_{p}} \int_{A} e_{z x}\left[\mathscr{H}\left(x-x_{p}\right)-\mathscr{H}\left(x-x_{p}-l_{p}\right)\right] z d A=\frac{1}{t_{p}} e_{z x}(x) \int_{A} z d A= \\
& =\frac{1}{t_{p}} e_{z x}(x) 2 s_{p} \int_{\frac{t_{w}}{2}}^{\frac{t_{w}}{2}+t_{p}} z d z=s_{p} e_{z x}(x)\left(t_{w}+t_{p}\right)
\end{aligned}
$$

Note that $e_{z x}$ was assumed constant along the thickness of the piezoceramic. Finally, because of Eq. 10, the second coupled equation can be expressed as:

$$
\int_{0}^{l_{p}} \eta(x) \frac{\partial^{3} u}{\partial x^{2} \partial t} d x+C_{p} \frac{d V}{d t}+\frac{V}{R_{e q}}=0
$$

\subsection{Torsional equation}

As already mentioned, under the assumptions made the torsional dynamic equilibrium is considered uncoupled from the electric forces. Thus, the torsional equation is (as given, for example, in ref. 23]):

$$
m(x) \frac{\partial^{2} u}{\partial t^{2}}(x, t)+\left[J(x)+m(x) d^{2}(x)\right] \frac{\partial^{2} \theta}{\partial t^{2}}(x, t)-G K(x) \frac{\partial^{2} \theta}{\partial x^{2}}(x, t)=M_{\theta}(x, t)
$$




\subsection{Aerodynamic loads}

The aerodynamic loads are derived from the two-dimensional unsteady potential theory of Theodorsen [1, and considered continuously distributed along the wingspan. The arbitrary motion of the aerofoil and the flap deflection can be evaluated by means of convolution of the Wagner's function, and the same procedure is applied for the gust encounter with the Kussner's function, as reported in 24].

According to this, the total lift and pitch moment can be expressed as a summation of the contributions of aerofoil motion, flap deflection and gust encounter:

$$
\begin{gathered}
L=L_{a}+L_{\delta}+L_{g} \\
M=M_{a}+M_{\delta}+M_{g}
\end{gathered}
$$

The expressions for three terms are treated separately in the supplementary material (Sec. 1.1). Lift and moments are evaluated at the elastic axis.

For the Wagner's function $\phi(t)$, the exponential approximation of Jones is used [25], which is:

$$
\phi(t)=1-A_{1} e^{-b_{1} \frac{U}{b} t}-A_{2} e^{-b_{2} \frac{U}{b} t} ;
$$

where the coefficients are $A_{1}=0.165, A_{2}=0.335, b_{1}=0.0455, b_{2}=0.3$.

The effect of gust is accounted using the Kussner's solution, with the following exponential approximation of the Kussner's function $\psi(t)$ :

$$
\psi(t)=1-A_{3} e^{-b_{3} \frac{U}{b} t}-A_{4} e^{-b_{4} \frac{U}{b} t} ;
$$

where the coefficients, proposed by Leishman [26, are $A_{3}=0.5792, A_{4}=0.4208, b_{3}=0.1393$, $b_{4}=1.802$.

The introduction of the aerodynamic loads in the form of unsteady aerodynamics formulation makes the problem a coupled set of Integro-Differential Equations (IDEs). This is due to the convolution integral terms present in Eqs. (1), (2), and (4) to (7) of the supplementary materiel. Those terms account for the past history of the system, which is needed when considering the unsteadiness of the flow field. A mathematical procedure exists to replace the integral terms with additional variables and equations describing their evolution. As a result, the set of IDEs can be 
expressed in terms of an expanded set of ODEs with an increased number of state variables. Such a procedure is the same reported in Ref. [10] or [27, and is described below.

A new set of variables is defined for those integral terms arising from convolution that cannot be expressed as linear functions of the structural variables (or their time derivatives). To obtain the dynamics of the new variables (the right part of Eqs. (10) of the supplementary material), the Leibniz integral role has been applied, namely:

$$
\frac{\partial}{\partial z} \int_{a(z)}^{b(z)} f(x, z) d x=\int_{a(z)}^{b(z)} \frac{\partial f}{\partial z} d x+f(b(z), z) \frac{\partial b}{\partial z}-f(a(z), z) \frac{\partial a}{\partial z}
$$

The new variables and their dynamics are described in details in the supplementary material (Sec. 1.2).

\subsection{Discretized equations}

The analytical model described above has been implemented in a finite element model, following the Weak Galerkin's Method [28]. The shape functions used for bending variables are the thirdorder polynomials of the Euler's beam formulation, while linear and step functions were used to model twist and piezoelectric variables, respectively.

For each element the vector $\boldsymbol{w}_{\boldsymbol{e}}$ contains all the nodal displacements of the element:

$$
\boldsymbol{w}_{\boldsymbol{e}}(t)=\left[\begin{array}{lll}
\boldsymbol{w}_{\boldsymbol{e} \mathbf{1}} & \mid & \boldsymbol{w}_{\boldsymbol{e} \mathbf{2}}
\end{array}\right]^{T}=\left[\begin{array}{lllllll}
u_{1}(t) & \varphi_{1}(t) & \theta_{1}(t) & \mid & u_{2}(t) & \varphi_{2}(t) & \theta_{2}(t)
\end{array}\right]^{T},
$$

where $u_{i}(t), \phi_{i}(t)$ and $\theta_{i}(t)$ are the vertical displacement, bending slope and twist of the $i$-th node, respectively.

The system is then assembled for $N$ elements and the constrained degrees of freedom are conveniently removed, giving:

$$
\left\{\begin{array}{l}
\boldsymbol{M} \ddot{\boldsymbol{w}}+\boldsymbol{K} \boldsymbol{w}-\boldsymbol{\Phi} \boldsymbol{V}=\boldsymbol{F}_{\boldsymbol{a}} \\
\boldsymbol{\Phi}^{T} \dot{\boldsymbol{w}}+C_{P} \dot{\boldsymbol{V}}+\frac{\boldsymbol{V}}{R_{e q}}=\mathbf{0}
\end{array}\right.
$$

where $\boldsymbol{\Phi}$ arises from the assembly of the electro-mechanical coupling matrices of each element containing a PZT insert (see Fig. 4). Each of these element matrices have the form:

$$
\boldsymbol{\Phi}_{\boldsymbol{e}}=\frac{1}{l_{e}} s_{p} e_{z x}\left(t_{w}+t_{p}\right)\left[\frac{d \boldsymbol{N}_{\boldsymbol{v}}}{d x}\right]_{\zeta_{p}}^{\zeta_{p}+l_{p} / l_{e}}
$$

where $\boldsymbol{N}_{\boldsymbol{v}}$ is the vector of bending shape functions. 


\subsubsection{Discretized aerodynamic loads}

The procedure to obtain discretized aerodynamic loads with the Galerkin's method is described in detail in the supplementary material (Sec. 1.3). This approach allows a simple match between the structure and the fluid, because the discrete loads are applied at each node, about the elastic axis. After developing Eqs. (13) and (14) (as shown in Sec. 1.1 of the supplementary material) and introducing the additional set of aerodynamic variables (using the technique described in Sec. 1.2 of the supplementary material), the equations for the aerodynamic lift and pitch moment can be explicitly expressed in terms of all the structural and aerodynamic state variables:

$$
\boldsymbol{F}_{e}=f\left(\ddot{\boldsymbol{w}}_{e}, \dot{\boldsymbol{w}}_{e}, \boldsymbol{w}_{e}, \boldsymbol{z}_{e}, \boldsymbol{z}_{\delta, e}, W_{g}, \delta_{e}, \dot{\delta}_{e}, \ddot{\delta}_{e}\right)
$$

In a more extended form, this allows the following matrix formulation:

$$
\begin{aligned}
\boldsymbol{F}_{e}= & \boldsymbol{A}_{M, e} \ddot{\boldsymbol{w}}_{e}+\boldsymbol{A}_{C, e} \dot{\boldsymbol{w}}_{e}+\boldsymbol{A}_{K, e} \boldsymbol{w}_{e}+\boldsymbol{A}_{z, e} \boldsymbol{z}_{e}+\boldsymbol{A}_{z_{\delta}, e} \boldsymbol{z}_{\delta, e} \\
& +\boldsymbol{A}_{g, e} W_{g}+\boldsymbol{A}_{\delta, e} \delta_{e}+\boldsymbol{A}_{\delta 1, e} \dot{\delta}_{e}+\boldsymbol{A}_{\delta 2, e} \ddot{\delta}_{e}
\end{aligned}
$$

with the vector $\boldsymbol{F}_{e}$ containing both forces and moment, and the aerodynamic variables, whose derivation and discretization are explained in details in the supplementary material (Sec. 1.2), being arranged as:

$$
\begin{aligned}
& \boldsymbol{z}_{e}(t)=\left[\begin{array}{lll}
\boldsymbol{z}_{e 1} & \boldsymbol{z}_{g, e} & \boldsymbol{z}_{e 2}
\end{array}\right]^{T}=\left[\begin{array}{llllllll}
z_{1}^{(1)}(t) & \ldots & z_{4}^{(1)}(t) & z_{7, e}(t) & z_{8, e}(t) & z_{1}^{(2)}(t) & \ldots & z_{4}^{(2)}(t)
\end{array}\right]^{T} \\
& \boldsymbol{z}_{\delta, e}(t)=\left[\begin{array}{ll}
z_{5}(t) & z_{6}(t)
\end{array}\right]^{T}
\end{aligned}
$$

where the apex ()$^{(i)}$ indicates the $i$-th node of the element. 


\subsubsection{Discretized piezo-aeroelastic equations}

The complete coupled set of equations describing the piezo-aeroelastic model is found combining the above aerodynamic model with Eq. (19). It yields the following:

$$
\left\{\begin{array}{c}
\boldsymbol{M}^{(3 N \times 3 N)} \ddot{\boldsymbol{w}}+\boldsymbol{K}^{(3 N \times 3 N)} \boldsymbol{w}-\boldsymbol{\Phi}^{\left(3 N \times N_{P}\right)} \boldsymbol{V}=\boldsymbol{A}_{M}^{(3 N \times 3 N)} \ddot{\boldsymbol{w}}+\boldsymbol{A}_{C}^{(3 N \times 3 N)} \dot{\boldsymbol{w}} \\
+\boldsymbol{A}_{K}^{(3 N \times 3 N)} \boldsymbol{w}+\boldsymbol{A}_{z}^{(3 N \times 8 N)} \boldsymbol{z}+\boldsymbol{A}_{z_{\delta}}^{\left(3 N \times 2 N_{F}\right)} \boldsymbol{z}_{\delta}+ \\
+\boldsymbol{A}_{g}^{(3 N \times 1)} W_{g}+\boldsymbol{A}_{\delta}^{(3 N \times 1)} \delta+\boldsymbol{A}_{\delta 1}^{(3 N \times 1)} \dot{\delta}+ \\
\quad+\boldsymbol{A}_{\delta 2}^{(3 N \times 1)} \ddot{\delta} \\
\boldsymbol{\Phi}^{T\left(N_{P} \times 3 N\right)} \dot{\boldsymbol{w}}+C_{P} \dot{\boldsymbol{V}}+\frac{\boldsymbol{V}}{R_{e q}}=\mathbf{0} \\
\dot{\boldsymbol{z}}=\boldsymbol{\Psi}^{(8 N \times 3 N)} \boldsymbol{w}+\boldsymbol{E}^{(8 N \times 8 N)} \boldsymbol{z}+\boldsymbol{Z}_{g}^{(8 N \times 1)} W_{g} \\
\dot{\boldsymbol{z}}_{\delta}=\boldsymbol{E}_{\delta}^{\left(2 N_{F} \times 2 N_{F}\right)} \boldsymbol{z}_{\delta}+\boldsymbol{Z}_{\delta}^{\left(2 N_{F} \times 1\right)} \delta
\end{array}\right.
$$

This system is written in state-space form. The three following matrices are introduced for convenience:

$$
\begin{aligned}
\boldsymbol{M}_{T} & =\boldsymbol{M}-\boldsymbol{A}_{M} \\
\boldsymbol{C}_{T} & =\boldsymbol{C}-\boldsymbol{A}_{C} \\
\boldsymbol{K}_{T} & =\boldsymbol{K}-\boldsymbol{A}_{K}
\end{aligned}
$$

Here, $\boldsymbol{C}$ is the structural damping matrix, which was set to zero in this work, but could be easily populated to include any damping model eventually required. The desired state-space representation is of the kind:

$$
\dot{\boldsymbol{x}}=\boldsymbol{A} \boldsymbol{x}+\boldsymbol{B} W_{g}+\boldsymbol{D} \tilde{\boldsymbol{\delta}}
$$

where:

$$
\boldsymbol{x}=\left[\begin{array}{c}
\boldsymbol{w} \\
\boldsymbol{v} \\
\boldsymbol{V} \\
\boldsymbol{z} \\
\boldsymbol{z}_{\delta}
\end{array}\right] ; \quad \boldsymbol{B}=\left[\begin{array}{c}
\mathbf{0} \\
\boldsymbol{A}_{g} \\
\mathbf{0} \\
\boldsymbol{Z}_{g} \\
\mathbf{0}
\end{array}\right] ; \quad \boldsymbol{D}=\left[\begin{array}{ccc}
\mathbf{0} & \mathbf{0} & \mathbf{0} \\
\boldsymbol{A}_{\delta} & \boldsymbol{A}_{\delta 1} & \boldsymbol{A}_{\delta 2} \\
\mathbf{0} & \mathbf{0} & \mathbf{0} \\
\mathbf{0} & \mathbf{0} & \mathbf{0} \\
\boldsymbol{Z}_{\delta} & \mathbf{0} & \mathbf{0}
\end{array}\right] ; \quad \tilde{\boldsymbol{\delta}}=\left[\begin{array}{c}
\delta \\
\dot{\boldsymbol{\delta}} \\
\ddot{\boldsymbol{\delta}}
\end{array}\right]
$$




$$
\boldsymbol{A}=\left[\begin{array}{ccccc}
\mathbf{0} & \boldsymbol{I} & \mathbf{0} & \mathbf{0} & \mathbf{0} \\
-\boldsymbol{M}_{T}^{-1} \boldsymbol{K}_{T} & -\boldsymbol{M}_{T}^{-1} \boldsymbol{C}_{T} & \boldsymbol{M}_{T}^{-1} \boldsymbol{\Phi} & -\boldsymbol{M}_{T}^{-1} \boldsymbol{A}_{z} & -\boldsymbol{M}_{T}^{-1} \boldsymbol{A}_{z_{\delta}} \\
\mathbf{0} & -\frac{1}{C_{P}} \boldsymbol{\Phi}^{T} & -\frac{1}{C_{P} R_{e q}} & \mathbf{0} & \mathbf{0} \\
\boldsymbol{\Psi} & \mathbf{0} & \mathbf{0} & \boldsymbol{E} & \mathbf{0} \\
\mathbf{0} & \mathbf{0} & \mathbf{0} & \mathbf{0} & \boldsymbol{E}_{\delta}
\end{array}\right]
$$

It is worth noting that the state vector $\boldsymbol{w}$ represents the structural nodal variables (vertical displacement, bending slope and twist), $\boldsymbol{v}$ represents their velocities, $\boldsymbol{V}$ represents the voltage outputs of the PZT elements, $\boldsymbol{z}$ contains the aerodynamic variables coupled to the structural degrees of freedom and the gust acting on each node, and $z_{\delta}$ are the aerodynamic states arising from the flap motion (two for each flapped element).

\subsubsection{Actuation energy}

This section presents the expressions for the aileron hinge moment in unsteady flow and for the corresponding actuation energy. From the unsteady aerodynamic theory of Theodorsen [1, the aerodynamic moment per unit span around the flap hinge is given by:

$$
\begin{aligned}
M_{h}(t)= & -\rho b^{2}\left\{\left[-2 T_{9}-T_{1}+T_{4}\left(a-\frac{1}{2}\right)\right] U b \dot{\theta}+2 T_{13} b^{2} \ddot{\theta}\right. \\
& \left.+\frac{1}{\pi} U^{2} \delta\left(T_{5}-T_{4} T_{10}\right)-\frac{1}{2 \pi} U b \dot{\delta} T_{4} T_{11}-\frac{1}{\pi} T_{3} b^{2} \ddot{\delta}+T_{1} b \ddot{u}\right\}+ \\
& -\rho U b^{2} T_{12} C(k)\left\{U \theta-\dot{u}+b\left(\frac{1}{2}-a\right) \dot{\theta}+\frac{1}{\pi} T_{10} U \delta+b \frac{1}{2 \pi} T_{11} \dot{\delta}\right\}
\end{aligned}
$$

Here, $C(k)$ is the Theodorsen's function, which is a complex function arising from Theodorsen's hypothesis of harmonic motion with reduced frequency $k$. The quantity in brackets in the last line of Eq. 27) represents the instantaneous vertical velocity of the fluid particle at the three-quarter chord point of the airfoil, and will be denoted as:

$$
w_{3 / 4}(t)=-\left\{U \theta-\dot{u}+b\left(\frac{1}{2}-a\right) \dot{\theta}+\frac{1}{\pi} T_{10} U \delta+b \frac{1}{2 \pi} T_{11} \dot{\delta}\right\}
$$

Making use of Wagner's function, an expression in the time domain of Eq. 27) can be found 
to be:

$$
\begin{aligned}
M_{h}(t)= & -\rho b^{2}\left\{\left[-2 T_{9}-T_{1}+T_{4}\left(a-\frac{1}{2}\right)\right] U b \dot{\theta}+2 T_{13} b^{2} \ddot{\theta}\right. \\
& \left.+\frac{1}{\pi} U^{2} \delta\left(T_{5}-T_{4} T_{10}\right)-\frac{1}{2 \pi} U b \dot{\delta} T_{4} T_{11}-\frac{1}{\pi} T_{3} b^{2} \ddot{\delta}+T_{1} b \ddot{u}\right\}+ \\
& -\rho U b^{2} T_{12}\left\{w_{3 / 4}(0) \phi(t)+\int_{0}^{t} \dot{w}_{3 / 4}(\tau) \phi(t-\tau) d \tau\right\}
\end{aligned}
$$

Therefore, with the same procedure used for airfoil lift and moment, the total hinge moment can be expressed as a function of the structural and aerodynamic state variables (detailed derivation can be found in the supplementary material, Sec. 1.4). The matrix discretized formulation is:

$$
\begin{aligned}
M_{h, e}= & \boldsymbol{H}_{1} \ddot{\boldsymbol{w}}_{e}+\boldsymbol{H}_{2} \dot{\boldsymbol{w}}_{e}+\boldsymbol{H}_{3} \boldsymbol{w}_{e}+\boldsymbol{H}_{4} \boldsymbol{z}_{e}+\boldsymbol{H}_{5} \boldsymbol{z}_{\delta, e} \\
& +\boldsymbol{H}_{6} \delta_{e}+\boldsymbol{H}_{7} \dot{\delta}_{e}+\boldsymbol{H}_{9} \ddot{\delta}_{e}
\end{aligned}
$$

Using the above results, the actuation power is given by:

$$
P_{a}(t)=M_{h}(t) \dot{\delta}(t)
$$

The energy required between $t_{0}$ and $t_{f}$ is:

$$
E_{a}(t)=\int_{t_{0}}^{t_{f}} P_{a}(t) d t=\int_{t_{0}}^{t_{f}} M_{h}(t) \dot{\delta}(t) d t
$$

These quantities are related only to the aerodynamic loads acting on the aileron hinge. Therefore, no friction and other losses are taken into account, so that the above equations provide an underestimation of the true value that will need to be corrected by experimental tests.

\section{Validation}

Before proceeding to the analyses and the results, the model was validated in its three main building blocks (structural dynamics, piezoelectric coupling, unsteady aerodynamics), and such validation is briefly presented in this Section. 


\subsection{Structural model}

The structural model was validated by running different types of analysis, ranging from modal analysis, harmonic analysis and forced response. Also, two integration methods were compared, the first implicit (Newmark method) and the second explicit (second-order Runge-Kutta method). For the analyses in the remainder, the latter was chosen. Results were compared with structural dynamics canonical test cases. As an example, Fig. 5 compares the results obtained with this model and those from reference 29. It shows the forced response to a sinusoidal vertical force applied at the tip of a clamped, uniform wing.

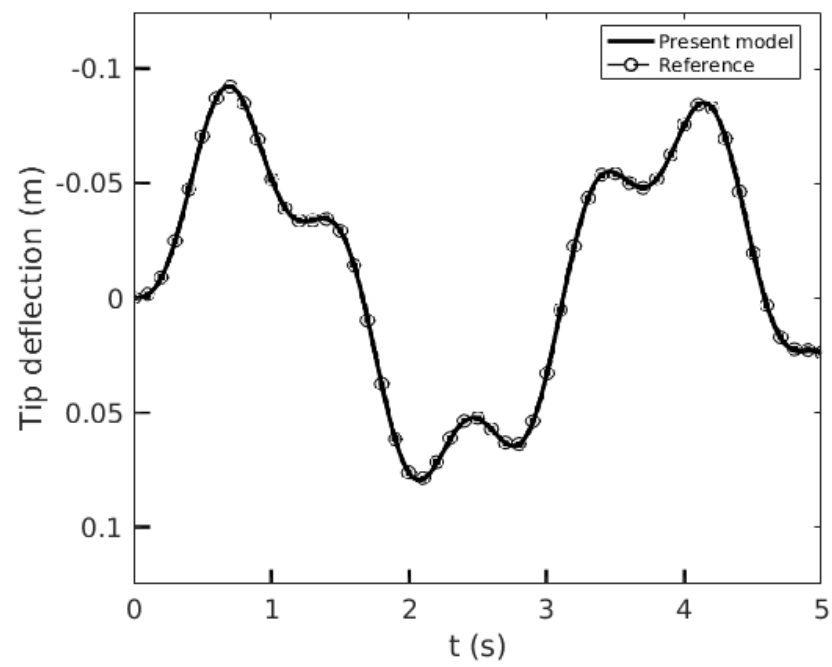

(a) Wing tip response.
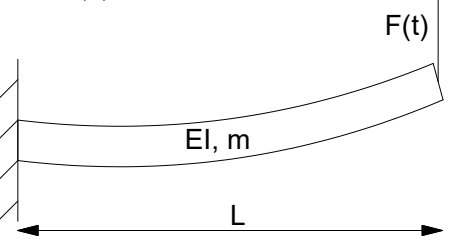

(b) Schematics of the structural

test-case.

Figure 5: Validation of the structural dynamics: vertical displacement of the wing tip due to a vertical harmonic force therein applied. Beam parameters: length $=16 \mathrm{~m}, a=d=0, m=0.75 \mathrm{~kg} / \mathrm{m}, E I=2 \cdot 10^{5} \mathrm{Nm}^{2}$; harmonic load: $\left.F(t)=F_{A} \sin (\omega t), F_{A}=10 \mathrm{~N}, \omega=2 \mathrm{rad} / \mathrm{s}\right)$. Reference data from [29]. 


\subsection{Coupled piezo-structural model}

The validation of the coupling between the structure and the piezoelectric inserts was conducted by examining a test case made of a clamped, homogeneous beam with a constant squared section, with two piezoelectric inserts symmetrically attached to the top and bottom surfaces at the root

of the beam. The tip was loaded with a vertical force, and an harmonic analysis was performed in order to determine the frequency response of the voltage output at the free surfaces of the PZT inserts. The results were compared with those obtained from a simulation run in Ansys Mechanical APDL (Release 15), using the same geometry and same number of elements. The parameters are summarised in Tables 1 and 2 .

\begin{tabular}{ll}
\hline \multicolumn{2}{c}{ Beam } \\
\hline Parameter & Value \\
\hline Length $(\mathrm{m})$ & 1.5 \\
Width $(\mathrm{m})$ & 0.05 \\
Height $(\mathrm{m})$ & 0.05 \\
Poisson's ratio & 0.33 \\
Elastic modulus $(\mathrm{Pa})$ & $7 \cdot 10^{7}$ \\
Density $\left(\mathrm{kg} / \mathrm{m}^{3}\right)$ & 2,700 \\
Tip load $(\mathrm{N})$ & $10 \cdot \sin (\omega t)$ \\
\hline \hline
\end{tabular}

Table 1: Piezo-structural model validation: beam properties.

To compare the model here developed with the results obtained with Ansys, 19 simulations were run in time domain, with different frequencies in the range 0 to $40 \mathrm{~Hz}$, and the amplitude of the voltage output from the tip node of the piezoelectric element was extracted. Note that a coarse discretization was used for these simulations, since the aim of this analysis was the comparison of the results obtained from the same physical model with two different solvers, and there was no need for a very refined mesh.

The comparison, reported in Fig. 6, shows a good matching, especially away from the resonance frequencies, where results cannot be accurate. 


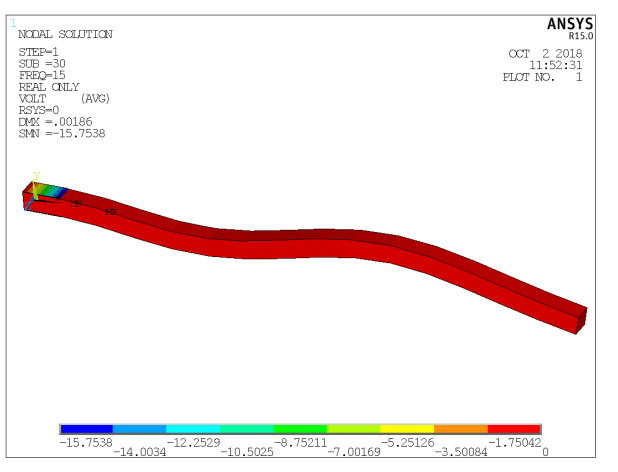

(a) Global view of voltage contour plot

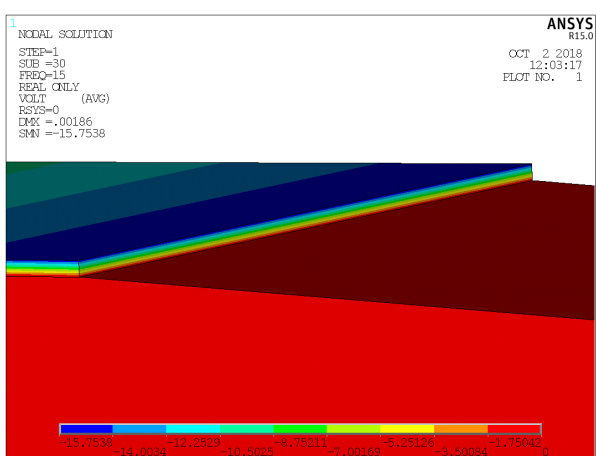

(b) Detail view of voltage contour plot

\section{Harmonic analysis of voltage output}

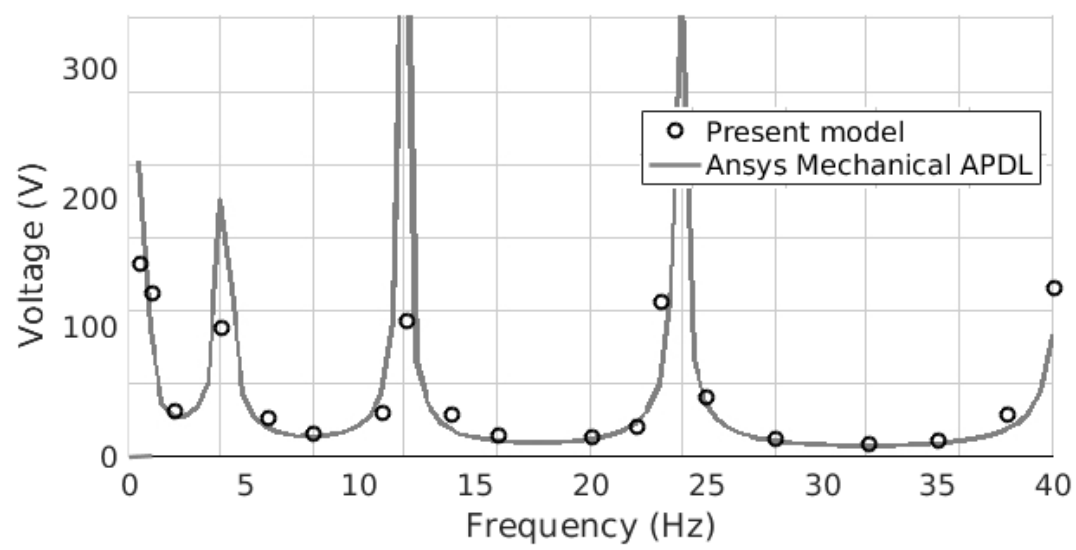

(c) Comparison of the frequency response

Figure 6: Validation of the piezo-structural model: the contour plot of voltage output during vibrations at excitation frequency $f=15 \mathrm{~Hz}$ is shown in (a) and (b); the results of the validation are plotted in (c), where each black circle represents the amplitude of the time response obtained with the present model. 


\begin{tabular}{lc}
\hline \multicolumn{2}{c}{ Piezoelectric inserts } \\
\hline Parameter & Value \\
\hline Length $(\mathrm{m})$ & 0.1 \\
Width $(\mathrm{m})$ & 0.05 \\
Height $(\mathrm{m})$ & $10^{-3}$ \\
Poisson's ratio & 0.33 \\
Piezoelectric stress coefficient $(\mathrm{C} / \mathrm{m})$ & -11.28 \\
Relative dielectric constant & 1,800 \\
Elastic modulus $(\mathrm{Pa})$ & $63 \cdot 10^{9}$ \\
Density $\left(\mathrm{kg} / \mathrm{m}^{3}\right)$ & 19,250 \\
\hline \hline
\end{tabular}

Table 2: Piezo-structural model validation: PZT properties.

\subsection{Unsteady aerodynamic model}

The unsteady aerodynamic model was validated for a two-dimensional profile, calculated with a different procedure. Such a comparison was performed to confirm that: a) the introduction of the new set of aerodynamic variables (see Section 2.5 was correctly implemented and successfully accounts for convolution terms; b) the loads predicted by the two-dimensional model, considered applied at each infinitesimal wing section, are properly integrated along the span-wise direction to give the right distribution and equivalent nodal loads. The reported test case is for forced sinusoidal motion in plunge according to the law $h(t)=\bar{h} \sin (k \tau)$ (Fig. 7), with amplitudes of $\bar{h}=0.2 b$, where the notation is that described in Fig. 3, and $\tau=t U / b$ is the nondimensional time. Three frequencies were considered, corresponding to the reduced frequencies $k=0.25,0.5$ and 0.75 , with $k=\omega b / U$. It can be seen that higher frequencies determine increasing perturbation in the flow, producing a more pronounced hysteresis and slope in the curve $C L-h$, which is supposed to stay flat in steady motion $(\dot{h} \rightarrow 0)$. 


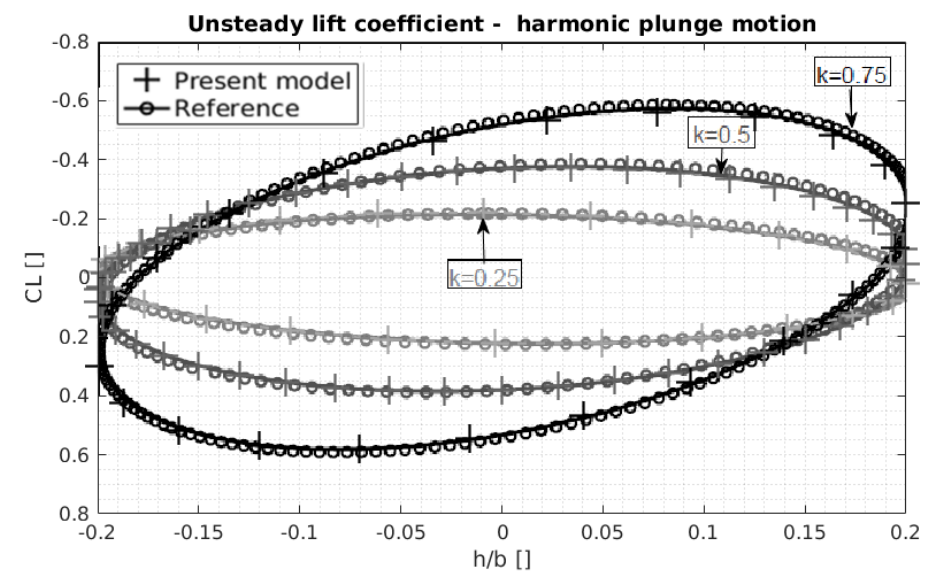

Figure 7: Validation of the unsteady aerodynamics: variation of lift coefficient with respect to plunge motion. Reference data from 30 .

\section{Test case description}

\subsection{Overview}

Details are now provided about the procedure followed and the settings used for the simulations. First of all, a modal projection of the structural variables was used to perform all the following analyses. In order to choose the right number of structural modes to maintain, some preliminary tests were run and compared with results from the full-order model. It was found that the first 8 modes (ordered by increasing frequency) are sufficient to have a good description of the voltage dynamics. The time step for the full-order model was set to 0.005 times the period of the highest frequency of the fully-coupled system. The projected model allows to increase the time step by 3 orders of magnitude (0.01 seconds) without showing appreciable differences from the full-order model, due to the fact that high-frequency modes give negligible contribution to the overall dynamics.

For gust analysis the relationship between gust wavelength and intensity at given altitude follows the procedure indicated by the US Federal Aviation Administration [31, where the correlation is reported in Fig. 8. Simulations were run for 4 seconds to allow structural vibrations to decay to zero. 


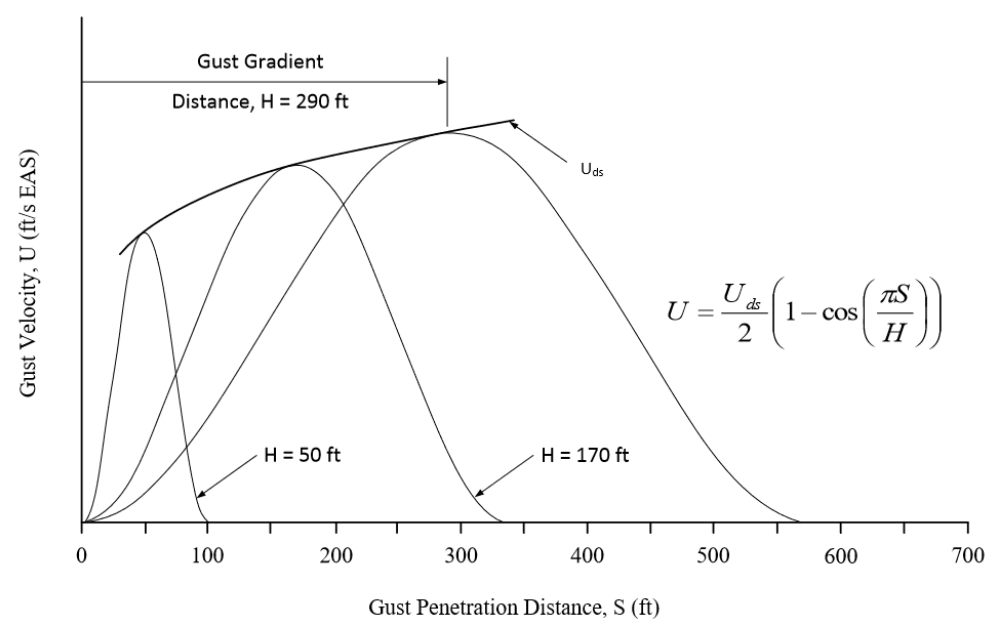

Figure 8: Typical one-minus-cosine gust velocity profiles, from Ref. [31.

\subsection{Aircraft configuration}

The results presented in this paper were obtained using the structural and geometric features of an actual HALE prototype [7]. These, together with the added PZT characteristics, are reported in Tables 3 and 4 .

Four installation layouts (see Fig. 9) were compared for harvesting performances, trying to exploit the contributions of multiple modal shapes and frequencies, in particular evaluating the amount of energy obtained being equal the weight of PZT material. In all of them attention was paid not to place any PZT element where deformations for the first four bending modes are small. In configuration A, the PZT were placed just at the root, where deformations are the largest. The other layouts contain more PZT inserts, placed in order to progressively cover a longer portion of the wing-span to exploit the deformations arising from higher-frequency modes. Simulations of discrete gust encounter were run for each layout using a one-minus-cosine gust input. For instance, Fig. 10 shows the response of the wing in terms of vertical displacement and twist at the tip, and the voltage and power outputs are reported in Fig. 11 (in this case the A layout was used).

To investigate harvesting performances, the effects of the flight condition (air speed and density) and that of the gust (amplitude and wavelength) were examined. A simple representative flight was chosen (see Fig. 12 with a cruise length of $1000 \mathrm{~km}$, cruise average altitude of $9000 \mathrm{~m}$ and two symmetrical climbs with rate of $25^{\circ}$, considered straight and covered at constant EAS. (climb from 


\begin{tabular}{lll}
\hline \hline & Wing & \\
\hline Parameter & Symbol & Value \\
\hline Semispan (m) & $L$ & 12 \\
Chord (m) & $c$ & 0.735 \\
Thickness (m) & $t_{w}$ & $0.12 c$ \\
Taper ratio & $t_{r}$ & 1 \\
Mass per unit length $(\mathrm{kg} / \mathrm{m})$ & $m$ & 1.254 \\
Elastic axis offset & $a$ & -0.5 \\
Distance of CG from elastic axis & $d$ & 0 \\
Aileron-hinge abscissa & $c_{F}$ & 0.5 \\
Polar moment of inertia about CG $(\mathrm{kg} \cdot \mathrm{m})$ & $J$ & 0.15 \\
Aileron span-wise location $(\mathrm{m})$ & $x_{F 1}, x_{F 2}$ & $3.0,12.0$ \\
Bending stiffness $\left(\mathrm{Nm}^{2}\right)$ & $E I$ & $3.126 \cdot 10^{4}$ \\
Torsional stiffness $\left(\mathrm{Nm}^{2}\right)$ & $G K$ & $1.102 \cdot 10^{4}$ \\
\hline \hline
\end{tabular}

Table 3: Wing parameters, from Ref. [7]

\begin{tabular}{lcl}
\hline \hline \multicolumn{3}{c}{ Piezoelectric inserts } \\
\hline Parameter & Symbol & Value \\
\hline Length $(\mathrm{m})$ & $l_{p}$ & 0.3 \\
Width $(\mathrm{m})$ & $s_{p}$ & 0.15 \\
Thickness $(\mathrm{m})$ & $t_{p}$ & 0.001 \\
Density $\left(\mathrm{kg} / \mathrm{m}^{3}\right)$ & $\rho_{p}$ & 7400 \\
Elastic modulus $(\mathrm{Pa})$ & $c_{x x}^{E}$ & $59 \cdot 10^{9}$ \\
Piezoelectric stress coefficient $(\mathrm{C} / \mathrm{m})$ & $e_{z x}$ & -14.68 \\
Dielectric constant $(\mathrm{F} / \mathrm{m})$ & $\varepsilon_{z z}^{S}$ & $1.731 \cdot 10^{-9}$ \\
Equivalent resistance $(\Omega)$ & $R_{e q}$ & $10^{5}$ \\
\hline \hline
\end{tabular}

Table 4: Piezoelectric parameters, mostly from Ref. 20] 


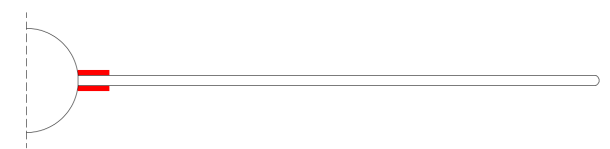

(A)

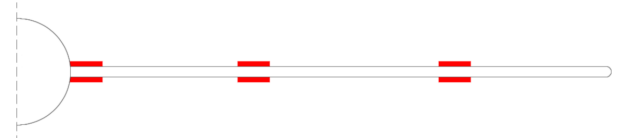

(C)

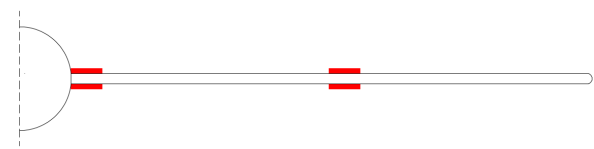

(B)

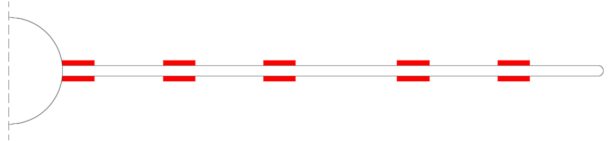

(D)

Figure 9: A schematic illustrating the four layouts of the PZT inserts along the wing.
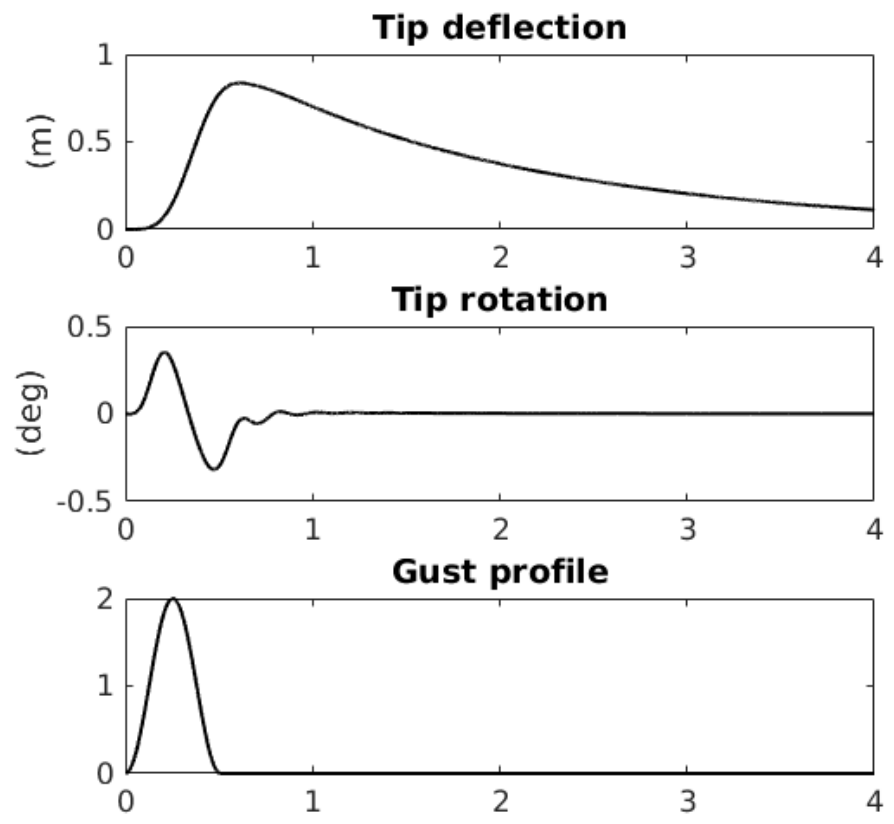

Figure 10: Tip displacement and rotation after a one-minus-cosine gust disturbance (layout $\mathrm{A}, U=16 \mathrm{~m} / \mathrm{s}, \rho=1.07$ $\left.\mathrm{kg} / \mathrm{m}^{3}, W_{g}=2 \mathrm{~m} / \mathrm{s}, H_{g}=4.07 \mathrm{~m}\right)$. 


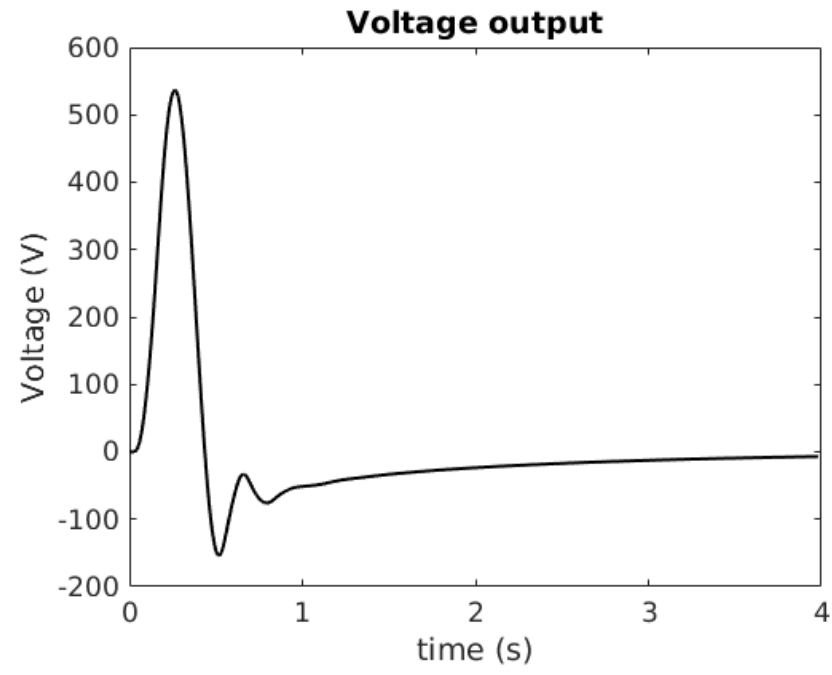

(a)

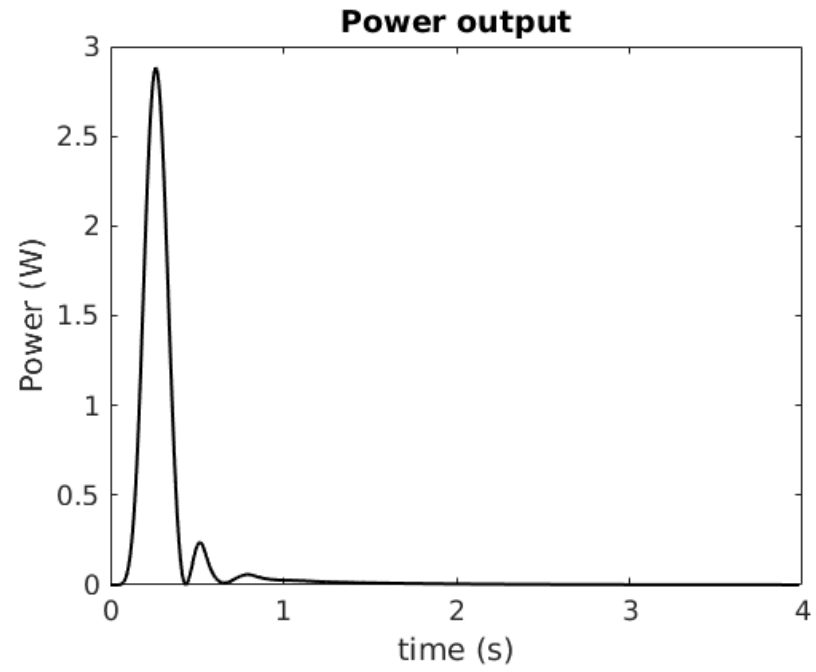

(b)

Figure 11: Voltage and power outputs from the simulation described in Fig. 10. A single pair of PZT inserts is installed at the root (configuration A). 
0 to $3000 \mathrm{~m}$, climb from 3000 to $6000 \mathrm{~m}$, climb from 3000 to $9000 \mathrm{~m}$, cruise at $6000 \mathrm{~m}$ ). For each phase, average air speeds and densities were used, as shown in Table 5 . Moreover, two different gust inputs are considered, in a range such that the intensity is neither too low for energy generation nor strong enough to affect structural safety. This resulted in the choice of gust amplitudes of $2 \mathrm{~m} / \mathrm{s}$ and $3 \mathrm{~m} / \mathrm{s}$. Three sets of simulations were run, once varying the flight condition, keeping the same gust speed, and once changing the gust input at the same flight condition. For every layout the same total amount of PZT material was used, and it was divided in equal parts for each PZT element of one layout. The harvested energy is calculated as the integral of the electric power flowing through the equivalent load resistance, and $V(t)$ depends on the aeroelastic oscillations of the wing:

$$
E(t)=\int_{t_{0}}^{t_{f}} P(t) d t=\int_{t_{0}}^{t_{f}} \frac{V^{2}(t)}{R_{e q}} d t
$$

From the results shown in Fig. 13 it can be noted that in all cases the most effective configuration is that in which all the PZT material is placed at the root of the wing, which agrees with the fact that the wing root experiences the largest deformations.

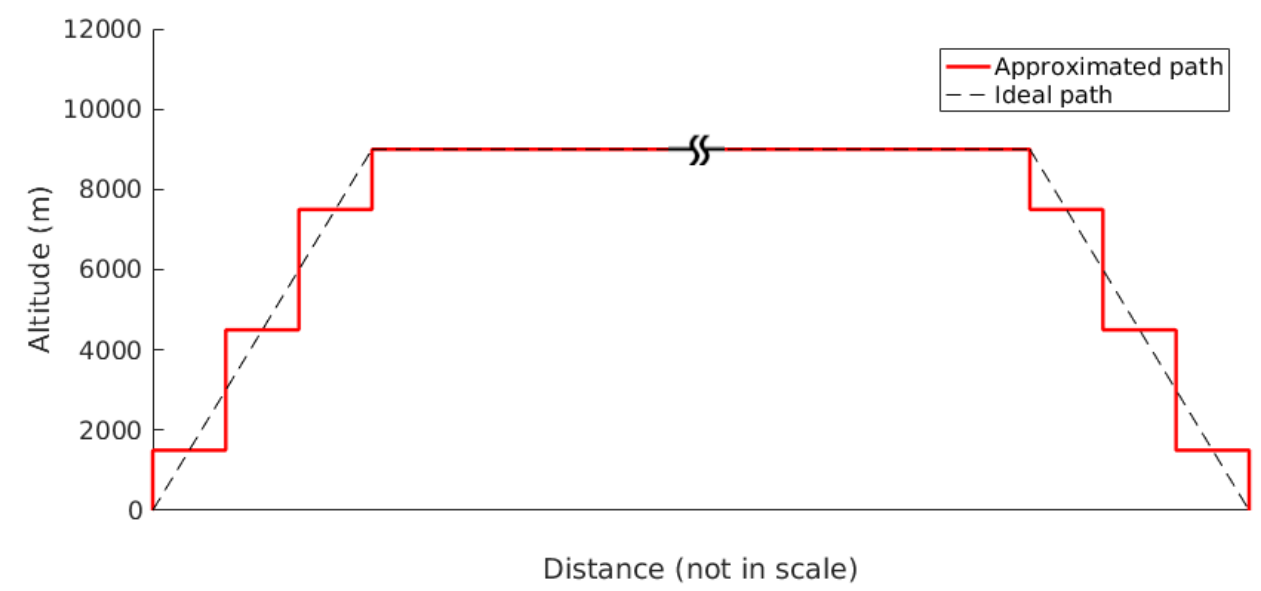

Figure 12: Schematic of the chosen representative flight.

\subsubsection{Control design}

Next, the energy required by an aileron actuator to achieve gust loads alleviation is evaluated, and compared with the energy harvestable by PZT inserts. This will allow assessing the feasibility of an energetically self-sufficient control system for wing oscillations. This Section describes the 


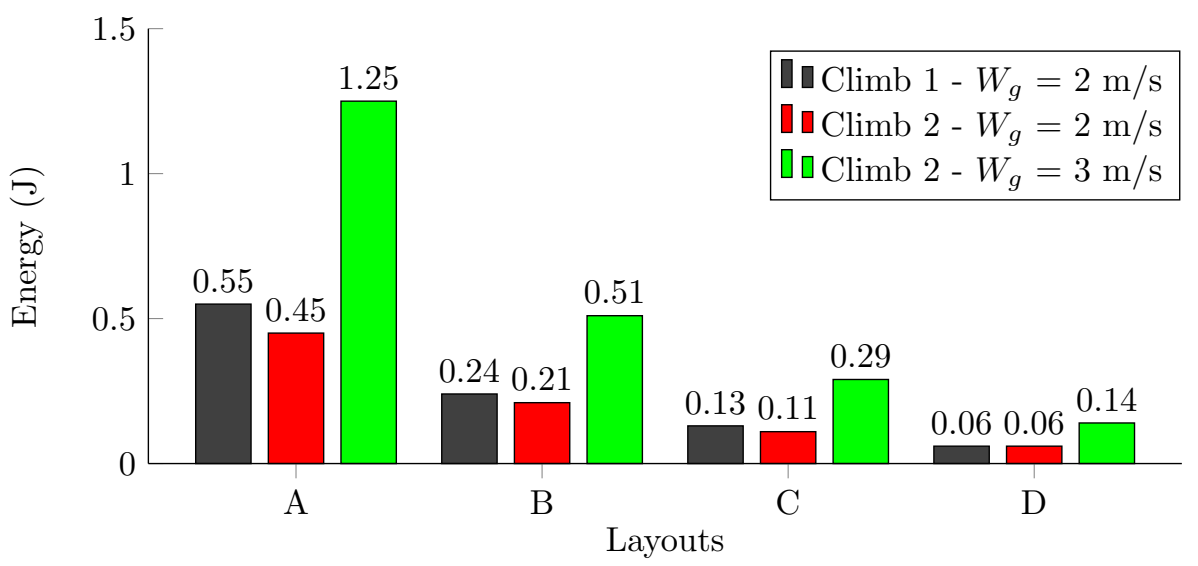

Figure 13: Comparison of harvesting performances of the four configurations. is of the kind:

$$
\delta(s)=\frac{N(s)}{(s+2)(s+20)} S_{x x}(s)
$$

It was found that a simple static gain in the numerator $\left(N(s)=k_{s}\right)$ in this case does not produce satisfactory results. Thus, a PID controller was considered to derive an appropriate form for $\left(N(s)=k_{s}+\frac{k_{i}}{s}+k_{d} s\right)$. A preliminary estimation for the set of gains was obtained by the Ziegler-Nichols tuning method. The initial set was then refined to pursue a better compromise between performance and control effort. It was found that the integral term is not really needed, so it was set $k_{i}=0$, and the final PD control law was obtained as:

$$
\delta(s)=\frac{(12.6+6.2 s) \cdot 10^{3}}{(s+2)(s+20)} S_{x x}(s)
$$

Results are reported and commented in Sec. 5.1. 


\section{Results}

This Section summarises the results relative to the energy balance of closed loop simulations between actuation and harvested energy (Section 5.1) and to the statistical evaluation of open loop harvesting performances during a whole flight mission (Section 5.2).

\subsection{Energy balance with active feedback control}

The open-loop and closed-loop responses to a gust disturbance are compared in Figs. 14 to 16

$$
n(u)=\frac{r(u)}{1000 l_{10}}
$$

In Eq. 36. $n(u)$ is the number of gusts exceeding $u$ per kilometre of flight, $l_{10}$ is a function of altitude (data are available from the ESDU Data Sheets [33]), representing the distance that must be flown at a given altitude in order that a gust with speed equal or greater than $3.05 \mathrm{~m} / \mathrm{s}$ be encountered, 


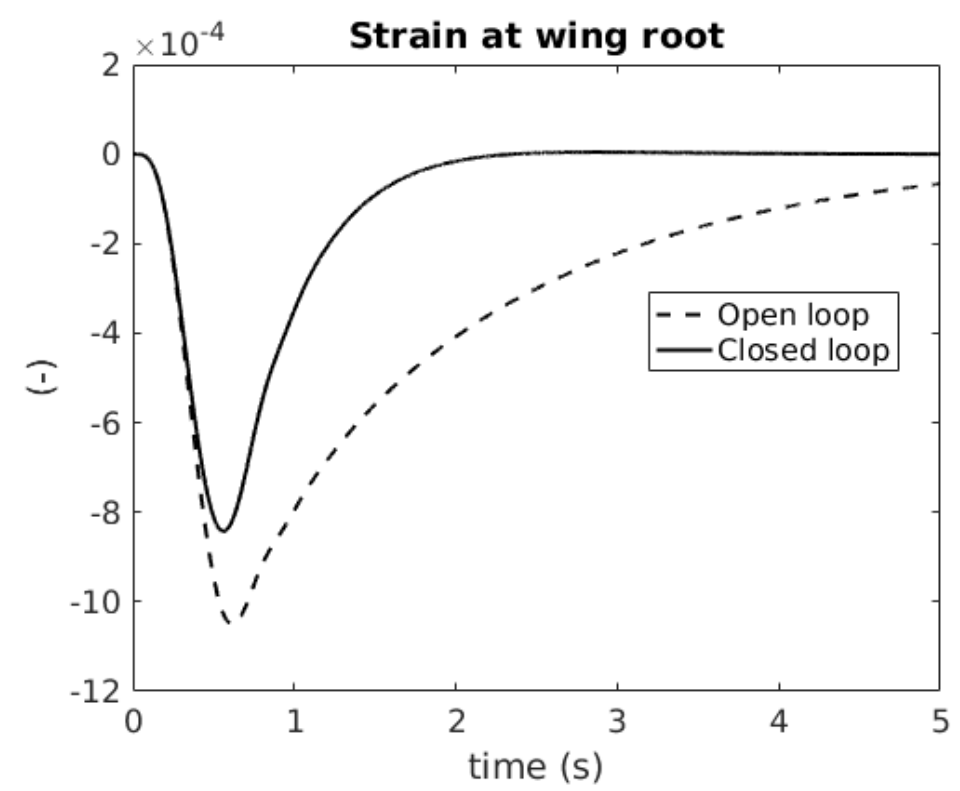

Figure 14: Comparison of the strain at the wing root for open-loop and closed-loop responses after gust disturbance $\left(U=16 \mathrm{~m} / \mathrm{s}, \rho=1.07 \mathrm{~kg} / \mathrm{m}^{3}, W_{g}=3 \mathrm{~m} / \mathrm{s}, H_{g}=6.1 \mathrm{~m}\right)$.

and $r(u)$ is the gust frequency distribution, which is the number of gusts of intensity $u$ for every 1000 gusts of intensity $3.05 \mathrm{~m} / \mathrm{s}$, and can be expressed by the following empirical equation:

$$
r(u)=3.23 \cdot 10^{5} u^{5.26}
$$

The number of gust encounters with velocity between $u_{1}$ and $u_{2}$ is obtained by integration:

$$
N_{12}=\int_{u_{1}}^{u_{2}} \frac{d n(u)}{d u} d u=\frac{1}{1000 l_{10}} \int_{u_{1}}^{u_{2}} d r(u)=\frac{1}{1000 l_{10}}[r(u)]_{u_{1}}^{u_{2}}
$$

The above expressions are dependent on $l_{10}$, which in turn depends on altitude. To evaluate the number of gust encounters of speed between $u_{1}$ and $u_{2}$ during climb another integration along altitude is needed, which is:

$$
N_{12}^{\text {climb }}=\frac{1}{1000}[r(u)]_{u_{1}}^{u_{2}} \int_{H_{1}}^{H_{2}} \frac{1}{l_{10}} \sin \gamma d H
$$

where $\gamma$ is the rate of climb, $H_{1}$ and $H_{2}$ are the minimum and maximum altitudes of the climb phase. A numerical evaluation of the above integral, from Ref. 32, is reported in Tab. 5. 

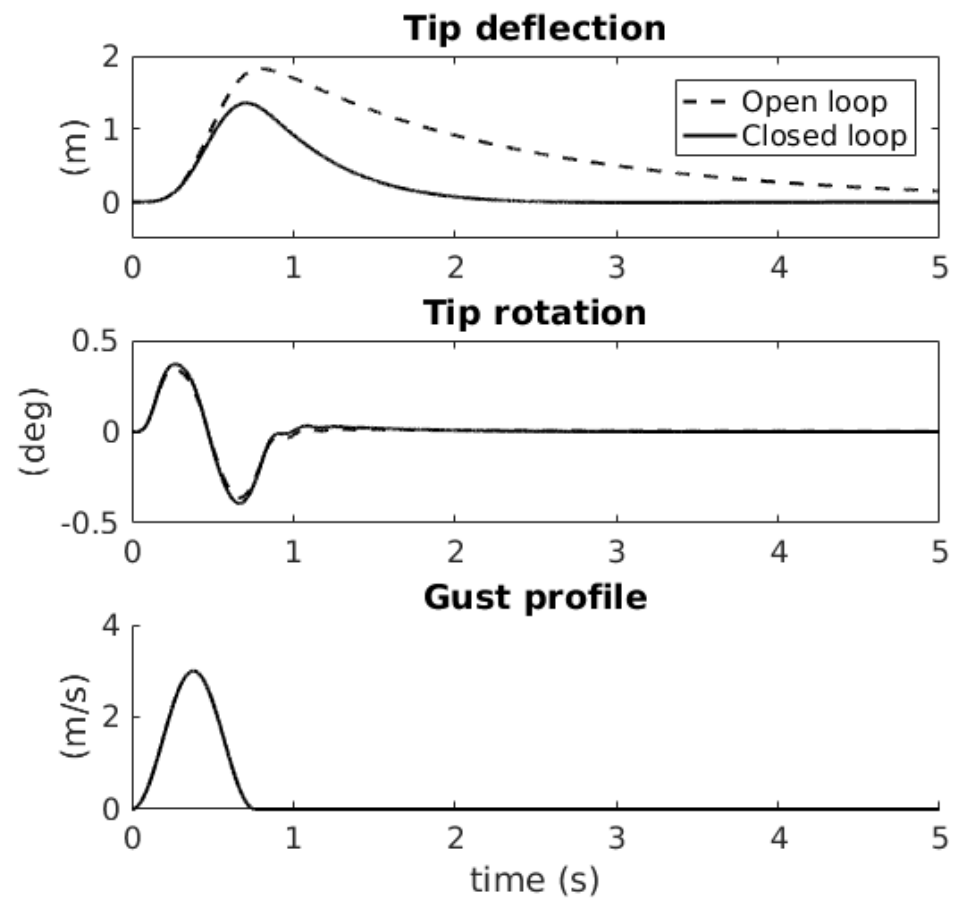

Figure 15: Comparison of the tip deflection and rotation for open-loop and closed-loop dynamics after a "one-minuscosine" gust disturbance. 


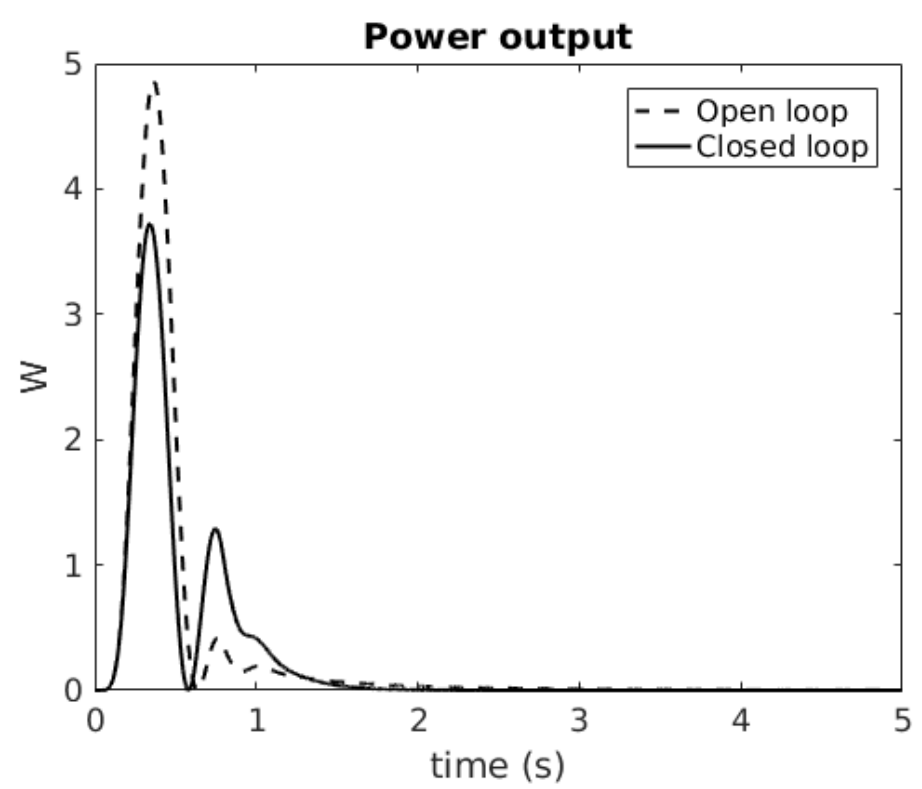

Figure 16: PZT power output in closed-loop and open-loop.

Equation (36) is plotted in Fig. 19 for different altitudes. Five gust speed intervals were considered, centred around 1, 2, 3, 4 and $5 \mathrm{~m} / \mathrm{s}$, as shown in Fig. 20. The integral was computed in the five areas delimited by the red lines. Only gusts of amplitude between 0.5 and $5.5 \mathrm{~m} / \mathrm{s}$ were taken into account. This choice arises from two main reasons: a) following the same approach of fatigue estimation, very low amplitude gust inputs are neglected because of their minor energy content and negligible effect in the harvesting process; b) since the category of aircraft here considered is very susceptible to turbulence, it was assumed that the vehicle does not operate when gust amplitude exceeds $5.5 \mathrm{~m} / \mathrm{s}$. These limitations furthermore make simulations to stay within the range of linear behaviour, and therefore in the range of validity of the numerical model presented in this work.

Simulations using discrete "one-minus-cosine" gust shapes were run for each of the five gust speeds above and for four flight phases (climb 1, climb 2, climb 3, cruise, see Fig. 12 and Table 5 ). The curves of Fig. 19 were discretized in the same way described in Fig. 20. The number of discrete events resulting from integration are reported in Fig. 21. Results in terms of energy harvested for each discrete event are summarized in Fig. 22. Multiplying each single energy contribution by the number of its occurrencies, the total amount of energy can be estimated.

Multiplying each single contribution reported in Fig. 22 by the number of its occurrencies over 

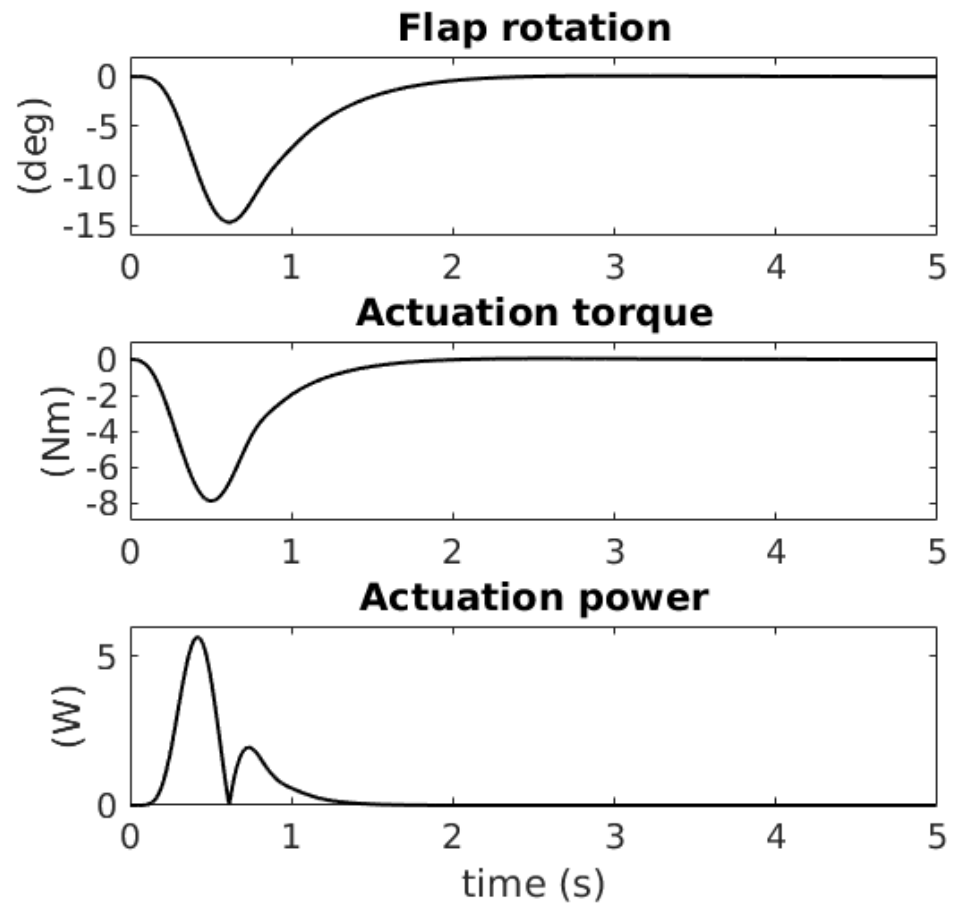

Figure 17: Actuation dynamics in the closed-loop simulation described above, according to the defined control law.

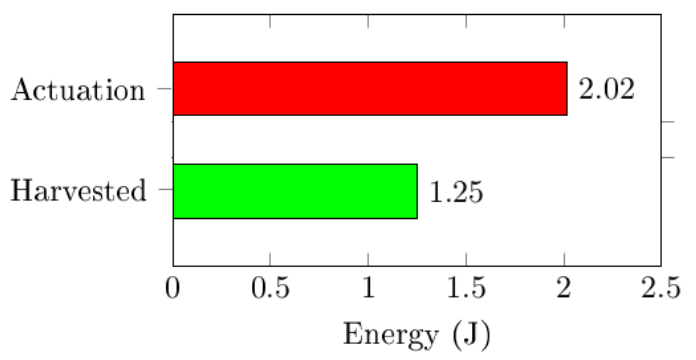

Figure 18: Balance between energy harvested and energy required for control actuation. 


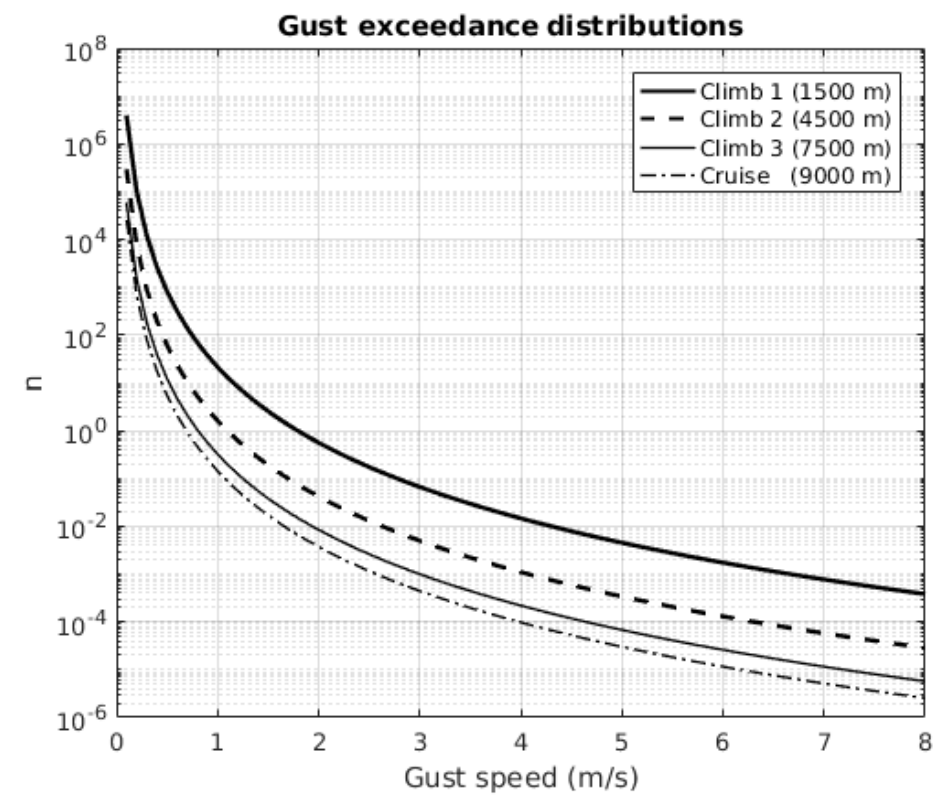

Figure 19: Gust exceedances distributions for different flight phases, each of them being characterised by its height and length (climb figures represent a single upward or downward climb).

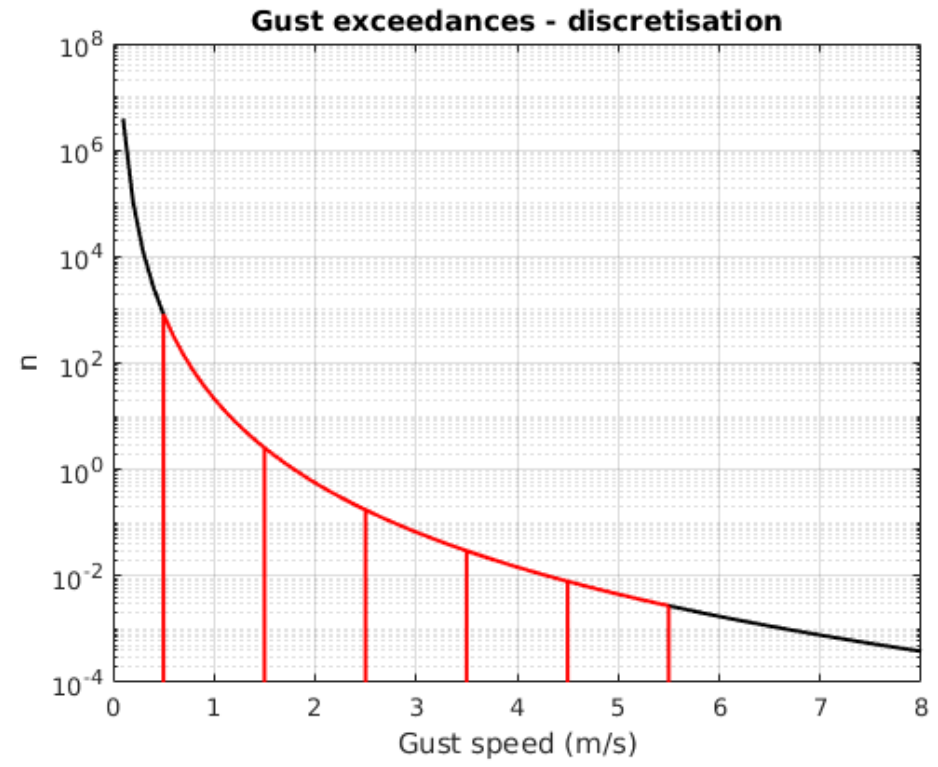

Figure 20: Discretisation of the gust exceedances distribution, here represented for altitude of $1500 \mathrm{~m}$. 


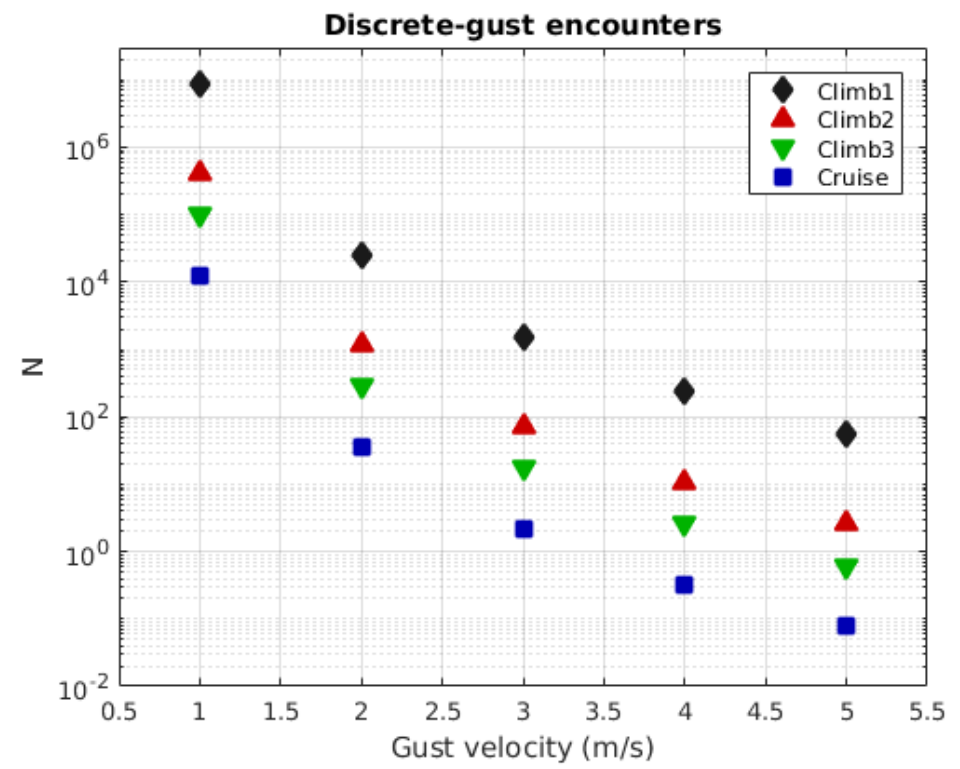

Figure 21: Number of gust encounters during flight phases (climb figures represent a single upward or downward climb).

\begin{tabular}{lccccc}
\hline \hline Flight phase & EAS $(\mathbf{m} / \mathbf{s})$ & Air density $\left(\mathrm{kg} / \mathbf{m}^{\mathbf{3}}\right)$ & $\boldsymbol{H}_{\mathbf{1}}(\boldsymbol{m})$ & $\boldsymbol{H}_{\mathbf{2}}(\boldsymbol{m})$ & $\int_{\boldsymbol{H}_{\mathbf{1}}}^{\boldsymbol{H}_{\mathbf{1}}} \frac{\mathbf{1}}{\boldsymbol{l}_{\mathbf{1 0}}} \boldsymbol{d} \boldsymbol{H}$ \\
\hline Climb 1 & 16.0 & 1.07 & 0 & 3000 & 303 \\
Climb 2 & 19.0 & 0.77 & 3000 & 6000 & 14 \\
Climb 3 & 22.5 & 0.57 & 6000 & 9000 & 3.4 \\
Cruise & 25.0 & 0.46 & 9000 & 9000 & - \\
\hline \hline
\end{tabular}

Table 5: Simulation parameters for discrete gust encounters. 


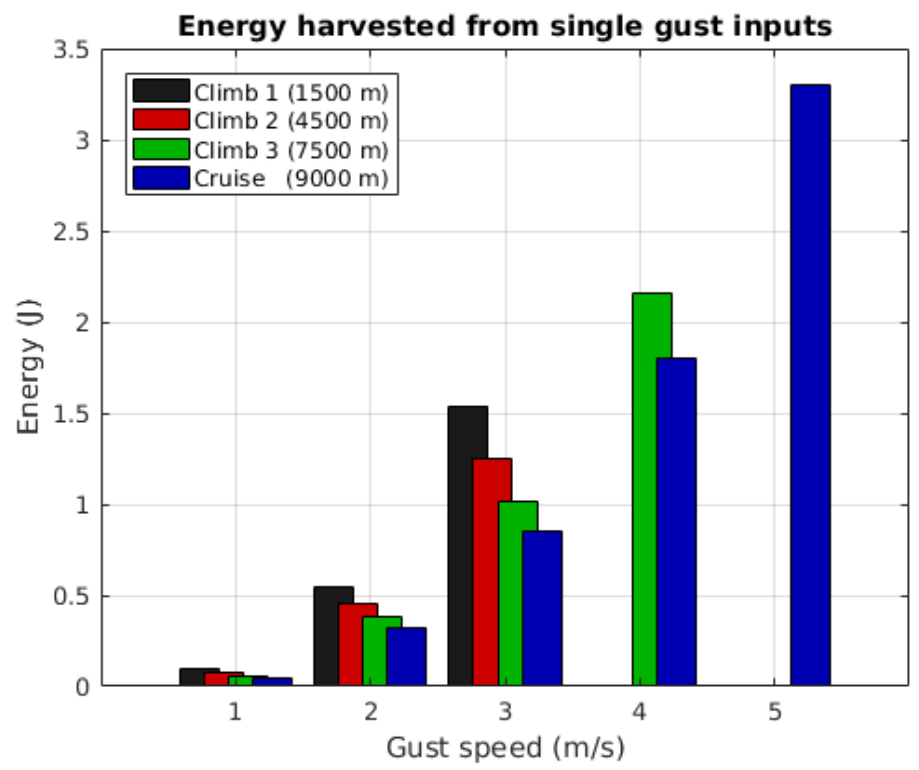

Figure 22: Energy harvested for single discrete gust encounters, for each phase of the flight.

the length of the flight, the total amount of energy harvestable is then estimated, and for this mission it amounts to $1.876 \cdot 10^{6} \mathrm{~J}$, or $521 \mathrm{Wh}$. The available technology allows modern light-weight electric aeroplanes to be equipped with batteries having an energy density of about $260 \mathrm{Wh} / \mathrm{kg}$ (Solar Impulse). Taking this value as a reference, PZT energy harvesting would provide, in the examined case, an amount of energy that would be stored in $2 \mathrm{~kg}$ of batteries, against around 330 grams of installed PZT material. It should be noticed that these results were obtained from a statistical evaluation, and therefore they are to be treated consequently: some flight missions will certainly experience a negligible turbulence compared with the levels considered in this paper, and conversely some others may encounter longer or stronger gust fields. This can also be affected by design limits, since in some cases very low turbulence levels are allowed for the aeroplane to fly. Also, for the same aeroplane missions can be different in terms of length and height, and it is much more likely to have relevant gust inputs when flying at lower heights. As a stochastic estimation, the presented results, although providing a slight improvement in efficiency, suggest that such EH technology is not likely to have a critical impact in the energetic balance of aerospace vehicles. In fact, in some cases the marginal energy income could not justify the added complexity. Nonetheless, the system could still play an important role in safety, since the harvested energy could be used for 

from gust-induced aeroelastic vibrations translates into a $2 \mathrm{~kg}$ saving of battery mass against just over $0.3 \mathrm{~kg}$ of installed piezoelectric material. An alternative and viable option consists of supplying low-power sensors for structural health monitoring. It is worth noting that attention was given to provide energy harvesting estimates as realistic as possible, overcoming the shortcomings of nearly

redundancy in the energy supply circuits. This would be useful especially in critical environmental situations where batteries could suffer failure or malfunctioning. One possible application is that of powering the aileron control system, whose energetic demand was found to be of the same order of magnitude of the income from PZT harvesters. Alternatively, the energy can be channelled into some key avionics to provide a secondary power source in the event of failure or shortage in the primary supply circuit. Moreover, other than safety, the electric signal from PZT inserts could be used for structural-health-monitoring purposes. In that case the PZT material should be conveniently distributed in the most critical regions of the structure. In principle, the PZT output could be switched to cover both the health-monitoring function and the emergency power supply when needed.

\section{Conclusions}

The limited amount of on-board stored energy constraints the mission of high-altitude longendurance unmanned aerial vehicles. This work addresses the challenge of harvesting energy from statistically representative gust encounters during a mission profile. Energy is obtained from piezoelectric inserts that are positioned on the upper and lower wing skin panels at various stations along the span of a flexible wing. Time-domain analyses are carried out solving a coupled system of equations for the four disciplines involved (unsteady aerodynamics, structural dynamics, piezoelectric and control system dynamics). A closed-loop gust load alleviation system is also developed, with $60 \%$ of the energy needed to operate the actuation system being provided by the energy harvested from aeroelastic vibrations. A statistical description of gust encounters along a representative mission profile is considered. It is found that, in statistical terms, the energy harvested all existing works on the topic.

\section{Supplementary material}

The supplementary material may be provided after acceptance. 


\section{Declaration of interests}

The authors declare that they have no known competing financial interests or personal relation-

ships that could have appeared to influence the work reported in this paper.

\section{References}

[1] T. Theodorsen, General theory of aerodynamic instability and the mechanism of flutter (NACA 口 Report No. 496) (1935) 24. arXiv:arXiv:1011.1669v3, doi:10.1017/CB09781107415324. 004

[2] J. Murua, H. Hesse, R. Palacios, J. M. R. Graham, Stability and Open-Loop Dynamics of Very Flexible Aircraft Including Free-Wake Effects, 52nd AIAA/ASME/ASCE/AHS/ASC Structures, Structural Dynamics and Materials Conference (2011) 1-21doi:10.2514/6.2011-1915. URL http://arc .aiaa.org/doi/10.2514/6.2011-1915

[3] C. M. Shearer, C. E. S. Cesnik, Nonlinear Flight Dynamics of Very Flexible Aircraft, AIAA Atmospheric Flight Mechanics Conference and Exhibt, AIAA paper 2005-5805, 2005.

[4] J. A. Paulino, A. Da Ronch, A. B. Guimarães Neto, F. J. Silvestre, M. A. V. Morales, On real-time simulation of flexible aircraft with physics-based models, 31st Congress of the International Council of the Aeronautical Sciences (ICAS), ICAS paper 2018-501, Belo Horizonte, Brazil, 09-14 September 2018.

[5] Solar impulse foundation (2016).

URL https://aroundtheworld.solarimpulse.com/

[6] E. T. Noll, J. M. Brown, M. E. Perez-Davis, S. D. Ishmael, G. C. Tiffany, M. Gaier, Investigation of the helios prototype aircraft mishap, NASA 2004.

[7] Y. Wang, F. Li, A. Da Ronch, Flight Testing Adaptive Feedback/Feedforward Controller for Gust Loads Alleviation on a Flexible Aircraft, AIAA Atmospheric Flight Mechanics Conference, Washington, D.C., 13-17 June 2017 (AIAA paper 2016-3100). doi:10.2514/6. 2016-3100. 
[8] Q. Zhou, D. Li, A. Da Ronch, G. Chen, Y. Li, Computational fluid dynamics-based transonic flutter suppression with control delay, Journal of Fluids and Structures 66 (2016) 183-206. doi:10.1016/j.jfluidstructs.2016.07.002. URL http://dx.doi.org/10.1016/j.jfluidstructs.2016.07.002

[ [9] Y. Wang, A. Da Ronch, M. Ghandchi-Tehrani, Adaptive feedforward control for gust-induced aeroelastic vibrations Aerospace, 2018,5(3),86 (aerospace:5030086). doi:10.3390. URL wWw .mdpi.com/journal/aerospace

[10] A. Da Ronch, N. D. Tantaroudas, K. J. Badcock, J. Mottershead, A nonlinear controller for flutter suppression: from simulation to wind tunnel testing, 55th AIAA/ASME/ASCE/AHS/ASC Structures, Structural Dynamics, and Materials Conference (AIAA paper 2014-0345) (2014) 1-19. doi:10.2514/6.2014-0345. URL http://arc .aiaa.org/doi/10.2514/6.2014-0345

510 [11] D. Li, Y. Wu, A. Da Ronch, J. Xiang, Energy harvesting by means of flow-induced vi【 brations on aerospace vehicles, Progress in Aerospace Sciences 86 (2016) 28-62. doi: $10.1016 / j$.paerosci.2016.08.001 URL http://dx.doi.org/10.1016/j.paerosci.2016.08.001

[12] V. Marsic, M. Zhu, S. Williams, Wireless sensor communication system with low power consumption for integration with energy harvesting technology, Telfor Journal 4 (2) (2012) 89-94.

[13] V. Raghunathan, A. Kansal, J. Hsu, J. Friedman, M. Srivastava, Design considerations for solar energy harvesting wireless embedded systems, Proceedings of the 4th international symposium घ on Information processing in sensor networks, 15-15 April 2005, Los Angeles, California doi: 10.1109/IPSN.2005.1440973.

[14] Y. Wu, D. Li, J. Xiang, A. Da Ronch, Piezoaeroelastic energy harvesting based on an airfoil with double plunge degrees of freedom: Modeling and numerical analysis, Journal of Fluids and Structures 74 (2017) 111-129. doi:10.1016/j.jfluidstructs.2017.06.009.

URL http://dx.doi.org/10.1016/j.jfluidstructs.2017.06.009

[15] J. Bae, D. Inman, A preliminary study on piezo-aeroelastic energy harvesting using a nonlinear trailing-edge flap, International Journal of Aeronautical and Space Sciences, 16 (3) (2015). 407- 
417.doi:http://dx.doi.org/10.5139/IJASS.2015.16.3.407.

URL http: //ijass . orgpISSN : 2093-274xeISSN : 2093-2480

[16] A. Abdelkefi, A. Nuhait, Modeling and performance analysis of cambered wing-based

【 piezoaeroelastic energy harvesters, Smart Materials and Structures, 22 (9), 095029 (2013) doi: 10.1088/0964-1726/22/9/095029.

[17] M. Piñeirua, O. Doare, S. Michelin, Influence and optimization of the electrodes position in a piezoelectric energy harvesting flag, Journal of Sound and Vibration. 346 (2015), 200-215.

[18] A. Bibo, M. Daqaq, On the optimal performance and universal design curves of galloping energy harvesters, Applied Physics Letters 104 (2), 023901 (2014). URL https : //doi .org/10.1063/1.4861599

[19] Y. Yang, L. Zhao, L. Tang, Comparative study of tip cross-sections for efficient galloping energy harvesting, Applied Physics Letters 102 (6), 064105 (2013).

[20] J. Xiang, Y. Wu, D. Li, Energy harvesting from the discrete gust response of a piezoaeroelastic wing: Modeling and performance evaluation, Journal of Sound and Vibration 343 (2015) 176193. doi:10.1016/j.jsv.2014.12.023

URL http://dx.doi.org/10.1016/j.jsv.2014.12.023

[21] C. Bruni, J. Gibert, G. Frulla, E. Cestino, P. Marzocca, Energy harvesting from aeroelastic vibrations induced by discrete gust loads, Journal of Intelligent Material Systems and Structures 28 (1) (2017) 47-62. doi:10.1177/1045389X16642533.

[22] Y. Wang, D. J. Inman, Simultaneous energy harvesting and gust alleviation for a multifunctional composite wing spar using reduced energy control via piezoceramics, J. Compos. Mater. 1 (47) (2013) 125-146.

[23] D. H. Hodges, G. A. Pierce, Introduction to Structural Dynamics and Aeroelasticity, Cambridge University Press, 2002.

[24] R. L. Bisplinghoff, H. Ashley, R. Halfman, Aeroelasticity, Dover Publications, Inc., 1955.

[25] R. T. Jones, The unsteady lift of a wing of finite aspect ratio, NACA report Nr. 681 (1940). 
[26] J. G. Leishman, Unsteady lift of a flapped airfoil by indicial concepts, Journal of Aircraft 31 (2) (1994) 288-297. doi:10.2514/3.46486. URL https://arc.aiaa.org/doi/abs/10.2514/3.46486

[27] B. H. K. Lee, L. Gong, Y. S. Wong, Analysis and Computation of Nonlinear Dynamic Response of a Two-Degree-of- Freedom System and its Application in Aeroelasticity, Journal of Fluids and Structures 11 (1997) 225-246.

[28] P. Papadopoulos, Introduction to the Finite Element Method, Department of Mechanical Engineering, University of California, Berkeley (2010). URL https : //www . mm . ethz . ch/CSM/FEMNotes .pdf

[29] A. Da Ronch, K. Badcock, Y. Wang, A. Wynn, R. Palacios, Nonlinear Model Reduction for Flexible Aircraft Control Design, AIAA Atmospheric Flight Mechanics Conference (2012) 123 doi: 10.2514/6.2012-4404

URL http://arc.aiaa.org/doi/10.2514/6.2012-4404

[30] J. Murua, Flexible aircraft dynamics with a geometrically-nonlinear description of the unsteady aerodynamics, PhD thesis, Imperial College London, May 2012.

[31] U.S. Federal Aviation Administration, Advisory Circular No 25.341-1 (2014).

[32] T. H. G. Megson, Aircraft Structures for Engineering Students, Fifth Edition, Elsevier Ltd., 2013.

[33] Average gust frequencies - subsonic transport aircraft. Technical Report ESDU No. 69023, Royal Aeronautical Sociaty, U.K. (2006). 